Published in final edited form as:

Nat Neurosci. 2016 December ; 19(12): 1619-1627. doi:10.1038/nn.4428.

\title{
Astrocytes mediate neurovascular signaling to capillary pericytes but not to arterioles
}

\author{
Anusha Mishra ${ }^{1}$, James P. Reynolds ${ }^{2}$, Yang Chen ${ }^{1}$, Alexander V. Gourine ${ }^{1}$, Dmitri A. \\ Rusakov $^{2}$, and David Attwell ${ }^{1}$ \\ ${ }^{1}$ Department of Neuroscience, Physiology \& Pharmacology, University College London, London, \\ UK \\ ${ }^{2}$ Institute of Neurology, University College London, London, UK
}

\begin{abstract}
Active neurons increase their energy supply by dilating nearby arterioles and capillaries. This neurovascular coupling underlies BOLD functional imaging signals, but its mechanism is controversial. Canonically, neurons release glutamate to activate metabotropic glutamate receptors (mGluR5) on astrocytes, evoking $\mathrm{Ca}^{2+}$ release from internal stores, activating phospholipase $\mathrm{A}_{2}$ and generating vasodilatory arachidonic acid derivatives. However, adult astrocytes lack mGluR5, and knock-out of the $\mathrm{IP}_{3}$ receptors that release $\mathrm{Ca}^{2+}$ from stores does not affect neurovascular coupling. We now show that buffering astrocyte $\mathrm{Ca}^{2+}$ inhibits neuronally-evoked capillary dilation, that astrocyte $\left[\mathrm{Ca}^{2+}\right]_{\mathrm{i}}$ is raised not by release from stores but by entry through ATP-gated channels, and that $\mathrm{Ca}^{2+}$ generates arachidonic acid via phospholipase D2 and diacylglycerol kinase rather than phospholipase $\mathrm{A}_{2}$. In contrast, dilation of arterioles depends on NMDA receptor activation and $\mathrm{Ca}^{2+}$-dependent NO generation by interneurons. These results reveal that different signalling cascades regulate cerebral blood flow at the capillary and arteriole levels.
\end{abstract}

\section{Introduction}

Functional hyperemia is the phenomenon by which active brain regions induce a local increase in blood flow to match their energy demands, via a process termed neurovascular coupling. Traditionally, regulation of cerebral blood flow was thought to occur at the level of arterioles 1-3, however, capillaries in the brain are also wrapped by contractile cells called pericytes4, which can respond to neuronal activity and control blood flow at a more local level than arterioles5,6. Although neurovascular coupling is the basis of blood oxygen level

Users may view, print, copy, and download text and data-mine the content in such documents, for the purposes of academic research, subject always to the full Conditions of use:http://www.nature.com/authors/editorial_policies/license.html\#terms

Correspondence to DA, d.attwell@ucl.ac.uk.

Accession codes: Not applicable

Author contributions:

A.M. and D.A. conceived the study. A.M. carried out all brain slice experiments, some immunocytochemistry, and analysed brain slice and in vivo data; J.P.R. performed in vivo experiments and analysed the resulting data; Y.C. carried out immunocytochemistry; A.V.G. and D.A.R. provided in vivo expertise; A.M. and D.A. wrote the paper; all authors revised the paper.

Competing Financial Interests:

The authors declare no competing interests. 
dependent (BOLD) functional magnetic resonance imaging (fMRI), an increasingly routine method used to measure brain activity in the clinic and in cognitive studies, our understanding of the underlying signalling mechanisms is still incomplete.

Neurovascular coupling can partly occur as a result of direct signalling from neurons to the vasculature7. However, over the last decade, a role for astrocytes, which have endfoot processes near blood vessels, has also been demonstrated, whereby neurons signal to astrocytes, which in turn release vasoactive substances onto vessels8. Initial data suggesting astrocyte-mediated neurovascular signalling came from experiments in which stimulating neurons led to a rise in astrocyte $\left[\mathrm{Ca}^{2+}\right]_{\mathrm{i}}$ as well as arteriole dilation1. It was further shown that raising astrocyte $\left[\mathrm{Ca}^{2+}\right]_{\mathrm{i}}$ evoked vascular dilations and constrictions $2,3,9$, which were produced by metabolites of arachidonic acid (AA) generated by phospholipase $\mathrm{A}_{2}\left(\mathrm{PLA}_{2}\right)$. Dilation occurred via the formation of prostaglandin $\mathrm{E}_{2}\left(\mathrm{PGE}_{2}\right)$ and epoxyeicosatrienoic acids (EETs), while production of 20-hydroxyeicosatetraenoic acid (20-HETE) resulted in constriction (see ref. 8 for review).

Although these findings were obtained in several laboratories, controversies still abound. Astrocyte $\mathrm{Ca}^{2+}$ signals may be too small or slow10, or too infrequent11, to have a causative role in neurovascular coupling. However, these conclusions were based on measuring $\mathrm{Ca}^{2+}$ signals within astrocyte cell bodies, rather than in the fine processes 12 of astrocytes near synapses which are presumably the first responders to neuronal activity. Indeed, recent in vivo studies have reported rapid, physiological stimulation-evoked $\left[\mathrm{Ca}^{2+}\right]_{\mathrm{i}}$ rises in astrocyte somata and endfeet in the somatosensory cortex 13 , and in the processes but not the somata of olfactory bulb astrocytes 14 .

A second controversy concerns how elevations of astrocyte $\mathrm{Ca}^{2+}$ concentration are generated. While these were originally thought to reflect activation of mGluR5 and downstream $\mathrm{IP}_{3}$-dependent release of $\mathrm{Ca}^{2+}$ from internal stores1-3, recent studies show that mGluR5 expression is downregulated in astrocytes from adult animals15. Furthermore, animals lacking $\mathrm{IP}_{3} \mathrm{R}_{2}$, the primary $\mathrm{IP}_{3}$ receptor in astrocytes, display unaltered neurovascular coupling16. Nevertheless, there are other mechanisms which could raise astrocyte $\left[\mathrm{Ca}^{2+}\right]_{\mathrm{i}}$, including $\mathrm{Ca}^{2+}$ permeable AMPA receptors17, NMDA receptors 18, ATP receptors 19 and TRPA1 channels20, and thus mediate astrocyte to vessel signalling.

Finally, it is unclear whether neurovascular coupling at the capillary level is mediated by the same pathways as that at the arteriole level. Although dilation of capillaries and arterioles both rely on relaxation of actomyosin, in pericytes and in arteriolar smooth muscle respectively, it seems plausible that local (capillary) and spatially broader (arteriolar) control of blood flow might be driven by different signalling pathways.

Here, we investigated the role of astrocytes in mediating neurovascular coupling in the cerebral cortex, in brain slices and in vivo. We provide the first direct demonstration that a rise in astrocyte $\left[\mathrm{Ca}^{2+}\right]_{\mathrm{i}}$ is necessary for neuronally-evoked capillary dilation to occur. We show that the source of $\mathrm{Ca}^{2+}$ involved in this process and its molecular effects are radically different from what was previously believed. We also show that arteriole dilation is not 
mediated by astrocyte $\mathrm{Ca}^{2+}$ signalling, but instead depends on NMDA receptor-mediated nitric oxide release (Supp. Fig. 1).

\section{Results}

\section{Neuronal activity evokes capillary dilation}

We assessed whether cerebral cortical capillaries can respond to electrically stimulated synaptic activity in cortical slices from P21 (adolescent) rats. Stimulation-evoked fibre volley and field excitatory post-synaptic currents (fEPSCs) were recorded in all experiments to confirm activation of the neuropil near the capillary being studied (Supp. Fig. 2). Vascular responses are known to be modulated by the oxygen $\left(\mathrm{O}_{2}\right)$ concentration in the tissue: physiological $\left[\mathrm{O}_{2}\right]$ produced by bubbling the superfusate with $20 \% \mathrm{O}_{2}$ results in larger dilations6,9,21. Therefore, all experiments reported here were conducted using $20 \% \mathrm{O}_{2}$. Furthermore, since vessels in brain slices do not have resting tone due to a lack of noradrenergic signalling from the locus coeruleus, and a lack of perfusion pressure and blood flow, a vasoconstricting agent is required to provide the resting tone upon which neuronally-evoked dilations normally occur22. Here, we bath-applied the thromboxane $\mathrm{A}_{2}$ analogue U46619 (200 $\mathrm{nM}$ ) for at least 5 minutes to pre-constrict cortical vessels prior to neuronal stimulation. Capillaries were identified as vessels $<10 \mu \mathrm{m}$ wide that lack a continuous layer of smooth muscle22 (Supp. Fig. 2). U46619 constricted capillaries by $18.7 \pm 0.7 \%$ ( $\mathrm{n}=213$ separate capillary regions (presumed locations of pericytes) in 112 vessels from 70 animals: Fig. 1a-b; Supp. Fig. 3) within minutes, without affecting electrically-evoked synaptic activity (Supp. Fig. 2c-d), and this constriction was maintained for at least $30 \mathrm{~min}$ (Supp. Fig. 3a). Electrically-stimulated neuronal activity then dilated the capillaries by $14.5 \pm 0.5 \%$ (Fig. 1a, b).

We first confirmed that stimulation-evoked capillary dilation resulted from neuronal activity and not direct stimulation of the vasculature. In the presence of tetrodotoxin (TTX, $500 \mathrm{nM}$ ), stimulation-evoked neuronal activity (the fibre volley and fEPSCs) was completely abolished (Supp. Fig. 2c) and capillary responses were also absent $(0.2 \pm 1.6 \%$ dilation, $n=11$; Fig. 1c, f) unlike for interleaved controls ( $14.0 \pm 1.6 \%$ dilation, $n=7$, significantly different, $\mathrm{p}=0.00008$; Fig. 1f). Blocking ionotropic glutamate receptors showed that post-synaptic activity was necessary for neurovascular signalling to capillaries. The AMPA/KA receptor blocker NBQX $(10 \mu \mathrm{M})$ inhibited stimulation-evoked fEPSCs (Supp. Fig. 2c, d) and reduced capillary dilation by $82.2 \%$ ( $\mathrm{p}=0.002$; Fig. $1 \mathrm{~d}, \mathrm{~g}$ ). In contrast, the NMDA receptor blocker D-AP5 $(25 \mu \mathrm{M})$ had no effect on stimulation-evoked capillary dilation (p=0.6; Fig. 1e, h). Thus, stimulation-evoked capillary dilation reflects action potential driven glutamatergic synaptic activity but does not depend on $\mathrm{Ca}^{2+}$ entry into neurons via NMDA receptors.

\section{Capillary dilation is mediated by $\mathrm{Ca}^{2+}$-dependent astrocyte signalling}

We next investigated whether astrocyte $\mathrm{Ca}^{2+}$ signalling mediates neuron-to-capillary signalling. To address this, astrocytes near the vessel of interest were whole-cell patchclamped and dialyzed with either a control internal solution containing $1 \mathrm{mM}$ EGTA (ethylene glycol-bis(2-aminoethylether)-N,N,N',N'-tetraacetic acid) or one containing 30 $\mathrm{mM}$ of the faster $\mathrm{Ca}^{2+}$ chelator BAPTA (1,2-bis(2-aminophenoxy)ethane-N,N,N',N'- 
tetraacetic acid). Spread of the pipette solution between astrocytes via gap junctions was visualized using the dye Alexa Fluor $488(40 \mu \mathrm{M})$. After 10-15 minutes of dialysis, the astrocyte network, including endfeet along the vessel of interest, was filled with Alexa Fluor 488 (Fig. 2a). Stimulating neuronal activity when astrocytes were dialyzed with the control (EGTA) internal solution evoked robust capillary dilations (16.2 $\pm 1.7 \%, \mathrm{n}=12$; Fig. 2b, c). However, when astrocytes were dialyzed with BAPTA to buffer rises in $\left[\mathrm{Ca}^{2+}\right]_{i}$, stimulationevoked dilation was reduced by $64 \%$ to $5.9 \pm 2.0 \%(n=17, p=0.0007$; Fig. $2 b, c)$. The free $\left[\mathrm{Ca}^{2+}\right]_{\mathrm{i}}$ in both the EGTA and BAPTA internal solutions was set to $\sim 24 \mathrm{nM}$, so the effects observed are not attributable to differences in baseline free $\left[\mathrm{Ca}^{2+}\right]_{\mathrm{i}}$, implying that a transient rise in astrocyte $\left[\mathrm{Ca}^{2+}\right]_{\mathrm{i}}$ in response to neuronal stimulation is, at least in part, necessary for neurovascular signalling to capillaries.

In some experiments, we imaged vessels as the internal solution spread from the patchclamped astrocyte into the endfoot processes, to observe whether buffering astrocyte $\mathrm{Ca}^{2+}$ rises had any effect on baseline capillary diameter. There was no significant change in the baseline diameter of the vessels when using either the control internal solution $(2.0 \pm 1.8 \%$ constriction in 4 capillaries, not significantly different from zero, $\mathrm{p}=0.3$ ) or the BAPTA internal (5.4 $\pm 3.2 \%$ dilation in 8 capillaries; not significantly different from zero, $\mathrm{p}=0.1$; diameter change in BAPTA was not significantly different from that in EGTA, $\mathrm{p}=0.2$ ).

\section{$\mathrm{P}_{2} \mathrm{X}_{1}$ receptors raise astrocyte $\left[\mathrm{Ca}^{2+}\right]_{\mathrm{i}}$}

Many mechanisms leading to a $\left[\mathrm{Ca}^{2+}\right]_{i}$ rise in astrocytes have been suggested. Group I metabotropic glutamate receptors (mGluR1/5) 23 and the ATP receptor $\mathrm{P}_{2} \mathrm{Y}_{1} 24$ are both Gprotein coupled receptors (GPCRs) associated with $\mathrm{G}_{\mathrm{aq}}$ signalling that induces $\mathrm{Ca}^{2+}$ release from internal stores by generating $\mathrm{IP}_{3}$. In particular, mGluR $1 / 5$ receptors have long been thought to be the primary cause of astrocyte $\left[\mathrm{Ca}^{2+}\right]_{\mathrm{i}}$ rises23. Recently, group II mGluRs were also shown to raise $\left[\mathrm{Ca}^{2+}\right]_{i}$ within astrocytes via an as yet undefined mechanism 25 . Furthermore, the $\mathrm{Ca}^{2+}$-permeable heteromeric ATP receptor $\mathrm{P}_{2} \mathrm{X}_{1 / 5} 19$ and transient receptor potential A1 (TRPA1) channels20 are also possible routes for $\mathrm{Ca}^{2+}$ influx into astrocytes. We tested the role of each of these receptors in mediating capillary-level neurovascular coupling. Stimulation-evoked capillary dilation was not reduced after bath application of a non-specific blocker of both group I and II mGluRs, (S)-MCPG (1 mM, p=0.1; Fig. 2d, i), the P2Y1 receptor blocker MRS2179 $(25 \mu \mathrm{M}, \mathrm{p}=0.8$; Fig. 2e, j) or the TRPA1 blocker A967079 (10 $\mu \mathrm{M}, \mathrm{p}=0.3$; Fig. 2f, k). However, the P2X 1 blockers NF449 (100 nM, Supp. Table 1) and NF023 $(5 \mu \mathrm{M})$ reduced the stimulation-evoked capillary dilation by $58 \%$ (p=0.0007; Fig. 2g, 1) and 94\% (p=0.001; Supp. Fig. 4d), respectively. Similar results were obtained using shorter stimulation durations than the $1 \mathrm{~min}$ used above (NF449 reduced dilation by $94 \%(\mathrm{p}=0.005)$ and $60 \%(\mathrm{p}=0.01)$ for $200 \mathrm{~ms}$ and $5 \mathrm{~s}$ stimulation, respectively; Supp. Fig. 4a-c), and in P45 mice (66\% reduction with NF449, p=0.00008 using $5 \mathrm{~s}$ stimulation; Supp. Fig. 4e). If $\mathrm{P} 2 \mathrm{X}_{1}$ receptors raise astrocyte $\left[\mathrm{Ca}^{2+}\right]_{\mathrm{i}}$ to evoke the dilation, then we should also be able to evoke dilation simply by activating this receptor. Indeed, a $5 \mathrm{~s}$ puff application of $\alpha, \beta$-methylene ATP ( $100 \mu \mathrm{M}$, see Methods), an agonist for P2X 26 , onto the neuropil induced a $10.7 \pm 2.3 \%$ dilation of cortical capillaries, whereas application of vehicle did not $(0.4 \pm 1.3 \%$ constriction, significantly different, $\mathrm{p}=0.0007$; Fig. $2 \mathrm{~h}, \mathrm{~m})$. These 
data suggest that capillary level neurovascular coupling occurs largely through a $\mathrm{P} 2 \mathrm{X}_{1}$ receptor-dependent pathway in astrocytes.

To study stimulation-evoked changes in $\left[\mathrm{Ca}^{2+}\right]_{\mathrm{i}}$ within astrocyte endfeet, we whole-cell clamped astrocytes to selectively fill them with the membrane-impermeant $\mathrm{Ca}^{2+}$ indicator dye Fluo4 $(50 \mu \mathrm{M})$, and a reference dye (Alexa Fluor 594, $40 \mu \mathrm{M}$ ) to allow ratiometric imaging (as $R=($ Fluo4 intensity)/(Alexa Fluor 594 intensity)). We observed spontaneous local $\mathrm{Ca}^{2+}$ transients in astrocyte cell bodies and processes, as previously reported27-29. Stimulating neuronal activity evoked an increase in $\left[\mathrm{Ca}^{2+}\right]_{i}$ in astrocytes $(\Delta R / R=41.4 \pm 11.7 \%$ in endfeet, $\mathrm{n}=9, \mathrm{p}=0.003$ compared to zero; $\Delta \mathrm{R} / \mathrm{R}=58.4 \pm 20.2 \%$ in processes, $\mathrm{n}=23, \mathrm{p}=0.006$; $\Delta \mathrm{R} / \mathrm{R}=60.2 \pm 24.3 \%$ in somata, $\mathrm{n}=13, \mathrm{p}=0.02$; Fig. 3a-c). The amplitude of this signal was reduced by $81 \%$ and $85 \%$ in endfeet and processes, respectively, by the $\mathrm{P} 2 \mathrm{X}_{1}$ receptor blocker NF449 $(\Delta R / R=7.9 \pm 3.1 \%$ in endfeet, $n=6, p=0.02$ compared to control data; $\Delta R /$ $\mathrm{R}=8.5 \pm 3.4 \%$ in processes, $\mathrm{n}=14, \mathrm{p}=0.02$; Fig. $3 \mathrm{~b}, \mathrm{c}$ ). NF449 did not significantly block the calcium rise in somata (Fig. 3c). These data are consistent with $\mathrm{P}_{2} \mathrm{X}_{1}$ receptor-mediated signalling within astrocytes mediating the capillary dilations seen in Figs. 1 and 2. In contrast, the mGluR blocker (S)-MCPG $(1 \mathrm{mM})$ did not alter the $\left[\mathrm{Ca}^{2+}\right]_{\mathrm{i}}$ changes in the endfoot, process or somata (Fig. 3c).

\section{Arachidonic acid metabolites mediating capillary dilation}

Astrocyte-mediated neurovascular coupling is thought to occur via the synthesis of AA by $\mathrm{Ca}^{2+}$-activated phospholipase $\mathrm{A}_{2}$ followed by metabolism into vasoactive substances 8 such as prostaglandins (by the activity of cyclooxygenase (COX)) or EETs (by the activity of epoxygenases). We tested the contribution of these enzymes using specific inhibitors. The COX1 inhibitor SC-560 $(1 \mu \mathrm{M})$ reduced the stimulation-evoked capillary dilation by $64 \%$ ( $p=0.0002$; Fig. 4a, d), but the COX2 inhibitor NS-398 (10 $\mu$ M; Fig. 4b, e) and the epoxygenase inhibitor PPOH (25 $\mu \mathrm{M}$; Fig. 4c, f) had no effect on the dilation. COX1 generates several prostaglandin derivatives, including the vasodilators $\mathrm{PGE}_{2}$ and $\mathrm{PGI}_{2}$. Blocking the $\mathrm{EP}_{4}$ receptor for $\mathrm{PGE}_{2}$ with $\mathrm{L}-161,982(1 \mu \mathrm{M})$ reduced the stimulation-evoked dilation by $72 \%$ ( $\mathrm{p}=0.004$; Fig. $4 \mathrm{~g}$, j). In contrast, blocking the IP receptor for $\mathrm{PGI}_{2}$ with CAY10441 (1 $\mu \mathrm{M}$ ) did not affect the dilation (Fig. 4h, k). Nitric oxide (NO) has also been shown to contribute to arteriolar vasodilation in the cortex30,31, however, when the NO

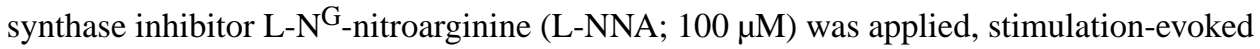
capillary dilation was not reduced (Fig. 4i, 1), implying that NO does not contribute to capillary dilation in the cortex. Thus, $\mathrm{PGE}_{2}$ generated by $\mathrm{COX} 1$ and acting on $\mathrm{EP}_{4}$ receptors is the primary vasoactive signal mediating capillary dilation.

We used immunohistochemistry to investigate the cellular location of the enzymes metabolising AA. We found COX1 labelling in processes along arterioles and capillaries that co-labelled for aquaporin $4\left(\mathrm{AQP}_{4}\right)$, a protein expressed highly in astrocyte endfeet (Supp. Fig. 5a). In contrast, COX2 did not colocalize with the astrocyte structural protein glial fibrillary acidic protein (GFAP), but was expressed diffusely in the neuropil with higher expression in neuronal somata (Supp. Fig. 5b). Antibodies against the CYP2C11 isoform of epoxygenase, reported to be the predominant epoxygenase in the rodent brains32, labelled $\mathrm{AQP}_{4}$-expressing endfeet along larger vessels, but not along capillaries (Suppl. Fig. 5c). 
Furthermore, antibodies against $\mathrm{PGE}_{2}$ synthase (PGES) also labelled GFAP-expressing astrocyte cell bodies, processes and endfeet (Supp. Fig. 5d). These findings are consistent with the functional data in Fig. 4 suggesting that $\mathrm{PGE}_{2}$ is the main vasoactive metabolite of AA that signals to capillaries, and is synthesized within astrocytes.

\section{PLD2, not PLA, initiates neurovascular coupling at the capillary level}

The $\mathrm{Ca}^{2+}$-dependent enzyme PLA 2 is thought to synthesize the AA which is converted into $\mathrm{PGE}_{2} 2,8,33$. We found that PLA 2 immunolabelling colocalized with GFAP positive astrocyte endfeet along capillaries (Supp. Fig. 6), suggesting a possible role for this enzyme. Surprisingly, however, stimulation-evoked capillary dilation was unchanged when $\mathrm{PLA}_{2}$ was blocked with its inhibitor MAFP $(10 \mu \mathrm{M}$, Fig. 5a, d). Thus, despite being in the correct cellular compartment, $\mathrm{PLA}_{2}$ is not the primary enzyme involved in the AA synthesis required for signalling to capillaries. We therefore sought other possible AA sources.

The enzymes phospholipase C (PLC) and PLD can produce AA via a multi-step process. PLC breaks down PIP $_{2}$ (phosphatidylinositol 4,5-bisphosphate) to DAG (diacylglycerol) and $\mathrm{IP}_{3}$, while PLD acts on membrane phospholipids to synthesize phosphatidic acid, which is then converted to DAG by phosphatidate phosphatase. DAG produced by PLC or PLD in this way can be further metabolized by DAG lipase (DAGL) to produce AA. A specific blocker of PLC, U73122 (10 $\mu \mathrm{M})$, did not reduce stimulation-evoked capillary dilation (Fig. $5 \mathrm{~b}, \mathrm{e})$. In contrast, a PLD specific blocker FIPI $(1 \mu \mathrm{M})$ reduced dilation by $64 \%(\mathrm{p}=0.0005$; Fig. 5c, f), suggesting that PLD plays a major role in synthesising AA. Two isoforms of PLD are expressed in mammals, PLD1 and PLD2, both of which are regulated34,35 by $\mathrm{Ca}^{2+}$. A specific inhibitor of PLD1, VU0155069 (500 nM), had no effect on stimulation-evoked dilation (Fig. 5g, j), however, a blocker of PLD2, CAY10594 (1 $\mu \mathrm{M})$ completely abolished the capillary dilation ( $\mathrm{p}=0.0002$; Fig. $5 \mathrm{~h}, \mathrm{k}$ ), suggesting that AA synthesis is PLD2 dependent. If so, then the downstream enzyme DAGL, which is required for AA production from DAG, should also be involved. Indeed, the DAGL inhibitor RHC80267 $(50 \mu \mathrm{M})$ also blocked the stimulation-evoked capillary dilation (reduced by $81 \%$, p=0.0004; Fig. 5i, 1), suggesting the PLD2-DAGL pathway as the mechanism for AA synthesis.

We considered whether PLD2 might, instead of being in the pathway for AA synthesis, be activated downstream of the $\mathrm{PGE}_{2}$ receptor $\mathrm{EP}_{4}$ in pericytes to cause the capillary dilation. However, there was no difference between $\mathrm{PGE}_{2}$-induced dilation of cortical capillaries in the absence $(8.1 \pm 1.7 \%)$ and presence $(8.5 \pm 2.1 \%)$ of the PLD blocker FIPI (Supp. Fig. 7), supporting our conclusion that the PLD2-DAGL pathway is upstream of AA synthesis.

Consistent with these results, immunolabelling for PLD1 showed that it is expressed diffusely in the neuropil and strongly in endothelial cells lining arterioles (Supp. Fig. 8a), but it was not in astrocyte endfeet, pericytes or capillary endothelial cells (Supp. Fig. 8a, b). In contrast, PLD2 immunolabelling occurred in GFAP-positive astrocyte endfeet on capillaries (Supp. Fig. 8c) and cell bodies (Supp. Fig. 8d), but not in pericytes or endothelial cells, consistent with a role in astrocyte-mediated neurovascular signalling to capillary pericytes. 


\section{Arteriole dilation is mediated by a different signalling pathway}

To compare the data above on capillary dilation with the dilation of arterioles evoked by neuronal activity, we carried out similar experiments imaging arterioles. U46619 preconstricted arterioles by $11.8 \pm 0.8 \%$ ( $n=36$ arterioles from 26 animals, Supp. Fig. 9). The neuronal stimulation-evoked dilation of arterioles $(7.0 \pm 0.7 \%, \mathrm{n}=36$, mean of all control data

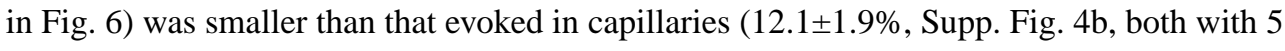
$\mathrm{s}$ stimulation). Remarkably, in contrast to the capillary dilation, the arteriole dilation was unaffected by dialysing the astrocyte network with BAPTA (Fig. 6a, b) or by blocking P2X receptors, PLD2 or $\mathrm{PLA}_{2}$ (Fig. 6c-e, h-i), indicating that a completely different signalling pathway, independent of astrocyte $\left[\mathrm{Ca}^{2+}\right]_{\mathrm{i}}$ changes, mediates arteriole dilation. However, again unlike the capillary dilation (Figs. $1 \mathrm{~h}, 4 \mathrm{l}$ ), arteriole dilation was strongly inhibited by blocking NMDA receptors ( $\mathrm{p}=0.008$, Fig $6 \mathrm{f}, \mathrm{j})$ or NO synthase $\left(\mathrm{p}=10^{-6}\right.$, Fig. $\left.6 \mathrm{~g}, \mathrm{k}\right)$.

\section{Neurovascular signalling in vivo}

To determine whether the ATP-dependent astrocyte signalling mechanism also mediates neurovascular coupling at the capillary level in vivo, we used 2-photon excitation fluorescence microscopy to image cortical capillaries and arterioles in vivo in anesthetised rats, with intravascular FITC-dextran to visualise the blood vessels (Fig. 7a-b, see Methods). We evoked neuronal activity in the somatosensory cortex by electrically stimulating the forepaw. The diameter of all imaged capillaries was $6.7 \pm 0.2 \mu \mathrm{m}(\mathrm{n}=102)$ and of arterioles was $13.4 \pm 0.5 \mu \mathrm{m}(\mathrm{n}=77)$. Forepaw stimulation evoked a dilation in $22 \%$ of capillaries and $24 \%$ of arterioles (Fig. 7c-e). In those vessels, capillary dilation averaged $29.3 \pm 5.8 \%$ and arteriole dilation averaged $10.9 \pm 2.2 \%$ (Fig. 7f).

Local infusion of the $\mathrm{P}_{2} \mathrm{X}_{1}$ blocker NF449 $(5 \mu \mathrm{M})$ into the cortical region did not significantly affect the percentage of capillaries dilating (reduced to $13 \%$, p=0.3, Fig. 7e). However, the capillary dilations that did occur were reduced by $68 \%$ in size to $9.5 \pm 1.8 \%$ $(\mathrm{p}=0.006$, Fig. $7 d, f)$. In contrast, NF449 did not significantly alter either the percentage of dilating arterioles $(18 \%, \mathrm{p}=0.6)$ or the magnitude of the arteriole dilations $(9.7 \pm 1.7 \%, \mathrm{p}=0.7$; Fig. 7c, e-f), just as in slices (Fig. 6h).

\section{Discussion}

Neurovascular coupling plays a crucial role in controlling cerebral blood flow, both physiologically and in disease. Capillary dilation generates a large portion of the blood flow increase evoked by neuronal activity, and thus is expected to contribute significantly to the BOLD signal6. In ischemia, pericytes constrict capillaries, contributing to the lack of reperfusion of the microvasculature that occurs after a thrombus is removed from an upstream artery6,36. Consequently, characterising the signalling mechanisms that regulate capillary and arteriole dilation is important for understanding the blood flow response to physiological activity and to disease. In this study, we have demonstrated that neurovascular coupling at the capillary and arteriole levels differ mechanistically (Supp. Fig. 1). Neurovascular coupling at the capillary level is largely dependent on astrocyte $\mathrm{Ca}^{2+}$ signalling, and our data reveal a new mechanism by which astrocytes alter their $\left[\mathrm{Ca}^{2+}\right]_{\mathrm{i}}$ in response to neuronal activity: influx of $\mathrm{Ca}^{2+}$ via the ionotropic ATP receptor $\mathrm{P} 2 \mathrm{X}_{1}$. Thus 
astrocyte $\left[\mathrm{Ca}^{2+}\right]_{\mathrm{i}}$ can be raised without a need for mGluR537 and $\mathrm{IP}_{3} \mathrm{R}_{2}$ mediated signalling, which have recently been suggested to be unnecessary for neurovascular coupling in adult animals15,16,38, and astrocyte $\mathrm{Ca}^{2+}$ transients observed in $\mathrm{IP}_{3} \mathrm{R}_{2}$ knockout mice39 may partly reflect activation of $\mathrm{P} 2 \mathrm{X}_{1}$ receptors. Our data are consistent with work showing that overexpression of an ecto-nucleotidase (to promote rapid ATP degradation) strongly reduces BOLD fMRI signals triggered by somatosensory stimulation in rats 40 . We also show that, although signalling to capillaries is mediated by AA metabolites, the synthesis of AA depends not upon PLA 2 as generally assumed2,8, but rather on PLD2 and DAGL activity. Furthermore, neuronal activity induced capillary dilation is unaffected by block of NO synthase (thus differing from the pericyte-mediated dilation we previously characterised in cerebellum6, presumably because of the difference in brain region (as the cerebellum expresses more NOS) and/or because dilation was evoked by glutamate superfusion in the latter study but by endogenous glutamate release here). In contrast, neurovascular signalling to cortical arterioles is not mediated by $\mathrm{P} 2 \mathrm{X}_{1}$, astrocyte $\mathrm{Ca}^{2+}$, PLD2 or $\mathrm{PLA}_{2}$ but, unlike cortical capillary dilation, requires the activation of NMDA receptors and production of NO.

Our data suggest that neuronal activity results in postsynaptic neurons (Fig. 1) releasing ATP, which acts on astrocyte ATP receptors containing P2X $\mathrm{X}_{1}$ subunits to produce a $\left[\mathrm{Ca}^{2+}\right]_{\mathrm{i}}$ rise (Figs. 2 and 3). This activates PLD2 (Figs. 5 and Supp. Fig. 8), resulting in AA synthesis via DAGL, and downstream metabolism by COX1 into vasodilatory $\mathrm{PGE}_{2}$, which is released onto capillary pericytes to induce dilation via the $\mathrm{EP}_{4}$ receptor (Fig. 4, Supp. Fig. 5). $P 2 X_{1}$ receptors are expressed in cortical astrocytes along with $P 2 X_{5}$ receptors 19 , which can together form heterotrimers and contribute to $\mathrm{Ca}^{2+}$ influx. The astrocyte $\mathrm{Ca}^{2+}$ influx causing capillary dilation (Figs. 2, 3, 7, Supp. Fig. 4) may be via $\mathrm{P} 2 \mathrm{X}_{1}$ homotrimers or $\mathrm{P} 2 \mathrm{X}_{1 / 5}$ heterotrimers 19 , as both are blocked by NF449 and activated by a, $\beta$-methylene ATP (puffed onto the neuropil; Fig. 2h, $\mathrm{m}$ and Supp. Fig. 10). Although it was previously reported that ATP is released40 from presynaptic terminals41, we show that NBQX blocks the capillary dilation, implying that postsynaptic glutamate receptor activation is needed for ATP release, at least in the cortex. The mechanism of this ATP release has yet to be investigated.

In contrast to capillary dilation, arteriole dilation does not depend on $\mathrm{P} 2 \mathrm{X}_{1}$ receptors, $\mathrm{PLA}_{2}$, PLD2 or astrocyte calcium signalling, but is dependent on NMDA receptor activation and nitric oxide synthesis (Fig. 6-7) as previously suggested30,31. It has been suggested that activation of NMDA receptors, by $\mathrm{Ca}^{2+}$-dependent release of D-serine from astrocytes, generates NO from eNOS in endothelial cells, and thus helps to dilate penetrating arterioles31. Our data showing that buffering astrocyte $\left[\mathrm{Ca}^{2+}\right]_{\mathrm{i}}$ does not inhibit arteriole dilation (Fig. 6a, b) argue against a role for astrocyte $\mathrm{Ca}^{2+}$ in triggering arteriole dilation in our experiments, and furthermore transcriptome data suggest there are no NMDA receptors on endothelial cells 42 . We therefore assume that the NO is generated by neuronal NOS, which is $\mathrm{Ca}^{2+}$-dependent and predominantly located in interneurons in the cortex43,44.

It has previously been suggested that, in the cortex, NO release is needed to maintain neurovascular coupling but not to mediate it 45 . This is similar to the idea that, in cortex 31 and in cerebellum6, NO serves to suppress the generation of the vasoconstrictor 20-HETE from AA while another AA derivative, $\mathrm{PGE}_{2}$, dilates the arterioles. We have shown that 
blocking AA production by inhibiting PLA 2 or PLD2 has no effect on the arteriole dilation evoked by neuronal activity (Fig. 6d, e, i), leading us to favour the idea that NO may directly mediate arteriole dilation in our preparation. However, we cannot rule out the possibility that AA is generated by PLC and DAG lipase, and that downstream generation of $\mathrm{PGE}_{2}$ (or EETs, see below) dilates the arterioles provided that NO suppresses 20-HETE formation.

The lack of dependence of arteriole dilation on astrocyte $\left[\mathrm{Ca}^{2+}\right]_{\mathrm{i}}$ changes contrasts with earlier work 1-3 in which mGluR agonists or $\mathrm{Ca}^{2+}$-uncaging evoked arteriole dilation by raising astrocyte $\left[\mathrm{Ca}^{2+}\right]_{\mathrm{i}}$. We assume this relates to the different kinds of stimuli applied: release of endogenous neurotransmitter glutamate from synapses in this paper, versus the generation of a more spatially extensive $\left[\mathrm{Ca}^{2+}\right]_{\mathrm{i}}$ rise by bath superfusion of an mGluR agonist or essentially simultaneous $\mathrm{Ca}^{2+}$-uncaging in several astrocytes. Consequently we cannot exclude the possibility that with other stimulation paradigms (or in other brain regions) mGluR-driven astrocyte $\mathrm{Ca}^{2+}$ signalling may contribute to arteriole dilation, although this mechanism may decrease in importance with age15.

Overall, our data indicate that two cellularly- and chemically-distinct $\mathrm{Ca}^{2+}$-dependent pathways mediate neurovascular coupling in response to neuronal activity evoked glutamate release (Supp. Fig. 1): ATP-evoked signalling in astrocytes generates $\mathrm{PGE}_{2}$ which dilates capillaries via pericytes, and glutamate-evoked NO release from interneurons dilates arterioles. Previous data6 suggest that the astrocyte-capillary pathway is faster, and quantitatively more important for increasing blood flow, than the interneuron-arteriole pathway, so our current data imply that purinergic signalling contributes significantly to generating BOLD signals.

We observed a similar block of capillary dilation after astrocyte $\mathrm{Ca}^{2+}$ buffering $(64 \%$ reduction: Fig. $2 \mathrm{c}$ ) and inhibition of $\mathrm{P} 2 \mathrm{X}_{1}$ receptors (58\% reduction: Fig. 21). The incomplete nature of this block (compared to that produced by inhibiting PLD2: Fig. 5k) may reflect an insufficient concentration of BAPTA or NF449 being applied. Alternatively, another mechanism might generate the remaining fraction of the response. We have ruled out direct signalling from neurons to pericytes via NMDA receptor mediated NO release30 (Fig. 1e, $\mathrm{h}$ and $4 \mathrm{i}, \mathrm{l}$ ), but other signals or $\mathrm{Ca}^{2+}$-independent (e.g. cyclic nucleotide) mechanisms in astrocytes could be involved.

Previous reports have suggested that astrocyte-mediated neurovascular signalling involves AA metabolites, and our data demonstrate that this is true for signalling to capillaries. Conceivably EETs may contribute to neurovascular signalling to arterioles under some conditions9,46,47, as we detected epoxygenase expression in astrocyte endfeet along larger vessels (but not in endfeet along capillaries (Supp. Fig. 5c) and EETs do not contribute to capillary dilation (Fig. 4c, f)6). Although AA production has been attributed to the activity of $\mathrm{Ca}^{2+}$-dependent48 PLA 2,8 , which is expressed in astrocytes33 (Supp. Fig. 6), we found that $\mathrm{PLA}_{2}$ is not involved in neurovascular coupling. Instead, another $\mathrm{Ca}^{2+}$-dependent phospholipase, PLD2, was responsible for AA production (Fig. 5h, k; Supp. Fig. 8c, d). In the brain, PLD1 may be expressed primarily in neurons or oligodendrocytes and PLD2 in astrocytes34,49. Furthermore, studies of the two PLD isoforms have suggested that PLD1 is expressed in endosomal compartments, depending on $\mathrm{Ca}^{2+}$ release from internal stores for 
activation, whereas PLD2 tends to be membrane associated and is activated by $\mathrm{Ca}^{2+}$ entry through ion channels34,35. Our findings suggest that astrocytic PLD2 is activated by $\mathrm{Ca}^{2+}$ entry through $\mathrm{P} 2 \mathrm{X}_{1}$ channels, which fits neatly with these data.

In conclusion, neuronal activity results in capillary dilation in a manner that is largely dependent on $\mathrm{Ca}^{2+}$-dependent signalling in astrocytes. The astrocyte $\left[\mathrm{Ca}^{2+}\right]_{i}$ rise causing dilation depends on ionotropic $\mathrm{P} 2 \mathrm{X}_{1}$ receptor activation, but not on GPCRs or TRPA1 channels. AA synthesis via a PLD2-DAGL pathway, and downstream metabolism into prostaglandin $\mathrm{E}_{2}$ by $\mathrm{COX} 1$, are necessary for capillary dilation, with the required synthetic enzymes being expressed in astrocytes. In contrast, neuronally-evoked arteriole dilation depends at least partly on the activation of neuronal NMDA receptors and subsequent synthesis and release of NO. These data demonstrate that astrocytes are important contributors to neurovascular coupling at the capillary level and suggest that capillaries, which contain most of the resistance to blood flow in the brain parenchyma50, could be specifically targeted therapeutically to increase blood flow in pathological conditions.

\section{Data availability statement}

The data that support the findings of this study are available from the corresponding author upon request.

\section{Methods}

\section{Animals}

Sprague-Dawley rats of both sexes were used in all experiments. Animal procedures were carried out in accordance with the guidelines of the UK Animals (Scientific Procedures) Act 1986 and European Directive 2010/63/EU. Each experiment was conducted on brain slices from at least three animals (at least one of each sex).

\section{Brain slice preparation}

As described previously22, $300 \mu \mathrm{m}$ thick coronal cortical slices were prepared from P21 rats on a vibratome in ice-cold oxygenated $\left(95 \% \mathrm{O}_{2}, 5 \% \mathrm{CO}_{2}\right)$ solution containing (in $\left.\mathrm{mM}\right) 93$ $\mathrm{N}$-methyl-D-glucamine chloride, $2.5 \mathrm{KCl}, 30 \mathrm{NaHCO}_{3}, 10 \mathrm{MgCl}_{2}, 1.2 \mathrm{NaH}_{2} \mathrm{PO}_{4}, 25$ glucose, $0.5 \mathrm{CaCl}_{2}, 20 \mathrm{HEPES}, 5 \mathrm{Na}$ ascorbate, $3 \mathrm{Na}$ pyruvate and 1 kynurenic acid. The slices were incubated at $34^{\circ} \mathrm{C}$ in the same solution for 15-20 min, then transferred to a similar solution with the NMDG-Cl, $\mathrm{MgCl}_{2}$ and $\mathrm{CaCl}_{2}$ replaced by (mM) $93 \mathrm{NaCl}, 1 \mathrm{MgCl}_{2}$ and $2 \mathrm{CaCl}_{2}$, and incubated at room temperature $\left(21-23^{\circ} \mathrm{C}\right)$ until used in experiments.

\section{Imaging of capillaries in brain slices}

Slices were perfused with bicarbonate buffered aCSF containing (in $\mathrm{mM}$ ) $124 \mathrm{NaCl}, 2.5$ $\mathrm{KCl}, 26 \mathrm{NaHCO}_{3}, 1 \mathrm{MgCl}_{2}, 2 \mathrm{CaCl}_{2}, 1 \mathrm{NaH}_{2} \mathrm{PO}_{4}, 10$ glucose, 1 Na-ascorbate heated to $31-35^{\circ} \mathrm{C}$ and gassed with $20 \% \mathrm{O}_{2}, 5 \% \mathrm{CO}_{2}$ and $75 \% \mathrm{~N}_{2}$. Capillaries were imaged using differential interference contrast (DIC) microsopy at 20-50 $\mu \mathrm{m}$ depth within layers III-VI of cortical slices containing the motor and prefrontal cortices, using a 40x water immersion objective, a Coolsnap HQ2 CCD camera, and ImagePro Plus acquisition software. Images were acquired every $5 \mathrm{~s}$, with an exposure time of $100 \mathrm{~ms}$. The pixel size was $160 \mathrm{~nm}$. The 
thromboxane $\mathrm{A}_{2}$ analogue $\mathrm{U} 46619(200 \mathrm{nM})$ was used to preconstrict capillaries in all experiments where the vessel response to stimulation was evaluated. Although the cerebral cortex is highly vascularized, the slicing procedure leaves many vessels unhealthy and unable to actively respond to stimuli22. We only analyzed vessels that preconstricted to U46619, in order to ensure that the vessels used in our experiments were healthy and responsive. Vessel internal diameters were measured by manually placing a measurement line perpendicular to the vessel (Fig. 1a) on the image at locations where constriction to U46619 occurred (presumed regions of active pericyte control) using Metamorph software. Change in diameter was quantified as a $30 \mathrm{~s}$ average centred around the largest response seen after stimulation, normalized to the baseline diameter. Experiments in which changes in focus occurred were excluded from further analysis. Data in the presence of blockers of signalling pathways were compared with interleaved control data obtained without the blockers to avoid confounds due to day-to-day variability in stimulation-evoked capillary responses. Control and drug experiments were randomly interleaved. To reduce experimenter bias, experiments were conducted and analyzed blind when possible (i.e. all experiments except when the drug was colored, e.g. NBQX).

\section{Stimulation protocol for brain slices}

High frequency $(100 \mathrm{~Hz})$ trains of short duration (200 ms [30-90 volt, $0.2 \mathrm{~ms}]$ ), medium duration (the short stimulation repeated once per sec for $5 \mathrm{sec}$ ) or long duration (the short stimulation repeated once per sec for 1 minute) were applied using an aCSF-filled patchpipette electrode placed 400-500 $\mu \mathrm{m}$ away from the imaged vessel. All stimulation durations evoked a capillary dilation with the same pharmacology (blocked by NF449: see Suppl. Fig. 3). All arteriole experiments were conducted using the $5 \mathrm{~s}$ medium duration stimulation. To confirm activation of the neurons, the field potential was monitored near the capillary of interest using a $4 \mathrm{M} \Omega$ patch pipette filled with aCSF (Supp. Fig. 2a, b), and only experiments where a field potential was detected were used for analysis. When characterizing field potentials in detail (Supp. Fig. 2), a $25 \mathrm{~s}$ long $12 \mathrm{~Hz}$ stimulation was used and the peak EPSC amplitude between 5 and $9 \mathrm{~ms}$ after stimulation was measured.

\section{Pharmacology in brain slices}

For all experiments, except those using L-161,982 and PPOH, vessels were preconstricted with $\mathrm{U} 46619$ which acts on thromboxane $\mathrm{A}_{2}$ receptors (unpublished data kindly provided by Ben Barres, similar to those at http://web.stanford.edu/group/barres_lab/brain_rnaseq.html, show that pericytes express this receptor). The drug of interest was then bath applied for at least 5 minutes before stimulation-evoked capillary responses were evaluated. For L-161,982 experiments, slices were treated with L-161,982 for 5 minutes before preconstriction was achieved with U46619 (applied for $5 \mathrm{~min}$ ) and stimulation-evoked dilations were then evaluated. This allowed us to confirm that $\mathrm{PGE}_{2}$ signalling via $\mathrm{EP}_{4}$ does not contribute to baseline capillary tone (constricted by $3.3 \pm 3.0 \%$; $\mathrm{p}=0.3$ ). Slices were incubated in $\mathrm{PPOH}$ for at least 1 hour before experiments and $\mathrm{PPOH}$ was included in all solutions (control and U46619-containing aCSF) to ensure that epoxygenase activity was blocked during stimulation experiments. A list of the drugs used is given in Supp. Table 1, along with the concentration and timeframe on which they have previously been shown to act. 


\section{a, $\beta$-methylene ATP puff experiments}

A $5 \mathrm{~s}$ puff of external solution containing $\alpha, \beta$-methylene ATP $(100 \mu \mathrm{M})$ was used to activate $\mathrm{P} 2 \mathrm{X}_{1}$ receptors. ATP can constrict retinal pericytes and arterioles directly5,51 and here we found the same effect when $a, \beta$-methylene ATP was bath applied to cortical slices $(8.4 \pm 2.7 \%$ constriction, $n=5)$. To avoid these direct effects of $\alpha, \beta$-meATP on the vessel, the puff pipette was positioned 100-150 $\mu \mathrm{m}$ downstream (with respect to the perfusion flow) from the capillary of interest, with the aim of activating astrocytes at that location which would then signal to the imaged vessel. Lack of spread of the puffed solution to the imaged vessel was confirmed by including a dye in the puffing pipette on some occasions (Supp. Fig. 10).

\section{Whole-cell patch-clamping of astrocytes}

Slices were superfused with bicarbonate-buffered solution as described above, bubbled with $20 \% \mathrm{O}_{2}, 5 \% \mathrm{CO}_{2}$ and $75 \% \mathrm{~N}_{2}$, and heated to $33-36^{\circ} \mathrm{C}$. Astrocytes were identified as cells with a soma of small diameter $(\sim 10 \mu \mathrm{m})$ that was not perfectly round. In some cases, slices were incubated at a very low concentration of Rhod-2 AM $(4 \mu \mathrm{M})$, which loads relatively selectively into astrocytes and NG2-positive oligodendrocyte precursor cells. Astrocytes were whole-cell clamped at $-80 \mathrm{mV}$ with 3-5 $\mathrm{M} \Omega$ patch pipettes with different internal solutions depending on the experiment being carried out. The control internal solution contained (in mM) $125 \mathrm{~K}$-gluconate, $2 \mathrm{NaCl}, 0.1 \mathrm{CaCl}_{2}, 10$ HEPES, $1 \mathrm{~K}_{4}$-EGTA, $2 \mathrm{MgCl}_{2}$, $2 \mathrm{Na}_{2}$ ATP, $0.5 \mathrm{Na}_{2} \mathrm{GTP}, 10 \mathrm{Na}_{2}$-phosphocreatine and 0.04 Alexa Fluor 488, with $\mathrm{pH}$ set to 7.1 using $\mathrm{KOH}$. The internal solution containing BAPTA (tetra-potassium salt) was similar but with the $\mathrm{CaCl}_{2}$ and EGTA replaced with (in mM) $3 \mathrm{CaCl}_{2}$ and 30 BAPTA (so that the free $\left[\mathrm{Ca}^{2+}\right]_{\mathrm{i}}$ was $\sim 24.5 \mathrm{nM}$ in both the control and the BAPTA internal solutions, calculated using MaxChelator (http://maxchelator.stanford.edu/webmaxc/webmaxcE.htm) with the temperature set to $35^{\circ} \mathrm{C}$ and ionic strength set to $145 \mathrm{mM}$ ) and with osmolarity differences compensated by lowering the K-gluconate concentration. Osmolarity measurements showed that $\mathrm{K}_{4}$-BAPTA does not dissociate completely so that correspondingly less compensation of osmolarity was needed. The solution contained (mM) $67 \mathrm{~K}$-gluconate, $2 \mathrm{NaCl}, 3 \mathrm{CaCl}_{2}, 10$ HEPES, $30 \mathrm{~K}_{4}$ BAPTA, $2 \mathrm{MgCl}_{2}, 2 \mathrm{Na}_{2} \mathrm{ATP}, 0.5 \mathrm{Na}_{2} \mathrm{GTP}, 10 \mathrm{Na}_{2}$ phosphocreatine and 0.04 Alexa Fluor 488, with pH set to 7.1 using $\mathrm{KOH}$. Patch-clamped cells were confirmed to be astrocytes morphologically by their arborization pattern revealed by dye filling and electrically by their large negative resting membrane potential $(-91.6 \pm 0.6 \mathrm{mV}, \mathrm{n}=33)$, low input resistance $(4.6 \pm 0.6 \mathrm{M} \Omega$ ) and passive $\mathrm{I}-\mathrm{V}$ relationship.

\section{Calcium imaging of astrocytes}

All neuronally-evoked astrocyte $\left[\mathrm{Ca}^{2+}\right]_{\mathrm{i}}$ imaging was carried out by confocal microscopy using a Zeiss LSM700 microscope. The internal solution used for $\mathrm{Ca}^{2+}$ imaging was similar to the control internal, but with added $50 \mu \mathrm{M}$ Fluo- 4 to sense $\mathrm{Ca}^{2+}$ and $40 \mu \mathrm{M}$ Alexa 594 as a reference dye to allow ratiometric imaging, and $\mathrm{CaCl}_{2}$ increased to $0.105 \mathrm{mM}$. The intensities of Fluo4 and Alexa 594 were measured using GECIquant39 in a region of interest (ROI), and a background intensity measured far from the filled astrocyte at each time point was subtracted from the value in the ROI at the same time point. Data were quantified as 
fractional changes in the ratio of background-subtracted Fluo4 fluorescence to Alexa 594 fluorescence. Images were acquired at $0.4 \mathrm{~Hz}$.

\section{Immunohistochemistry}

$200 \mu \mathrm{m}$ thick coronal cortical slices were incubated in aCSF bubbled with $95 \% \mathrm{O}_{2}$ and $5 \%$ $\mathrm{CO}_{2}$ containing $1 \mu \mathrm{M}$ isolectin $\mathrm{B}_{4}$ conjugated to Alexa 488 (which binds to a-D-galactose residues in the vascular basement membrane52) for 30 minutes to label vessels, then washed with aCSF and fixed in 4\% paraformaldehyde for 1 hour. Slices were then washed 3 times in phosphate-buffered saline (PBS) and incubated in a blocking solution (comprised of $0.05 \%$ Triton X-100, 10\% horse serum and 1\% bovine serum albumin prepared in PBS for $1 \mathrm{hr}$ ) at room temperature. Slices were incubated with the primary antibody for $48-72 \mathrm{hrs}$ at $4{ }^{\circ} \mathrm{C}$ with agitation, washed 3 times with PBS, incubated with the secondary antibody overnight at $4{ }^{\circ} \mathrm{C}$ with agitation and washed again 3 times with PBS. The primary and secondary antibody solutions were prepared in PBS containing $0.005 \%$ Triton X-100, $1 \%$ horse serum and $0.1 \%$ bovine serum albumin. Controls to test for non-specific labeling of the secondary antibody were carried out in exactly the same manner, except that slices were incubated in just the vehicle (PBS containing $0.005 \%$ Triton $\mathrm{X}-100,1 \%$ horse serum and $0.1 \%$ bovine serum albumin) during the primary antibody incubation step. The slices were then mounted with VectaShield hard set mounting medium containing DAPI to label nuclei.

Immunohistochemistry experiments were conducted on three separate occasions on tissue from three different animals. Primary antibodies used were: chicken GFAP (Abcam, ab4674, 1:1000), rabbit AQP 4 (Santa Cruz, sc-20812, 1:500) or goat AQP 4 (Santa Cruz, sc-9888, 1:500), goat COX1 (Abcam, ab22720, 1:1000), goat COX2 (Abcam, ab23672, 1:1000), goat PGES (Santa Cruz, sc-12268, 1:500), rabbit PLD1 (Santa Cruz, sc-25512, 1:300), rabbit PLD2 (Santa Cruz, sc-25513, 1:200), mouse PLA2 (Santa Cruz, sc-454, 1:300) and rabbit CYP2C11 (Abcam, ab3571, 1:300). Secondary antibodies used were: donkey anti-chicken Alexa 644 (Molecular Probes, 1:1000), donkey anti-chicken Cy5 (Jackson Laboratories, 1:1000), donkey anti-rabbit Alexa 647 (Molecular probes, 1:1000), donkey anti-goat Alexa 568 (Molecular probes, 1:1000), donkey anti-rabbit Alexa 555 (Molecular Probes, 1:1000) and donkey anti-mouse Cy3 (Jackson Immunoresearch Laboratories, 1:500). Immunolabelled slices were imaged using a Zeiss LSM700 confocal microscope.

\section{In vivo experiments: preparation}

Experiments were conducted in male Sprague-Dawley rats (4 to 6 weeks of age). Animals were initially anaesthetised using isoflurane (5\% induction, $2 \%$ maintenance). The femoral artery was cannulated for continuous blood pressure recording, as well as periodic blood gas monitoring. Following cannulation, a mixture of urethane (a single dose of $0.75 \mathrm{~g} / \mathrm{kg}$ ) and alpha-chloralose (an initial dose of $50 \mathrm{mg} / \mathrm{kg}$ supplemented with $10 \mathrm{mg} / \mathrm{kg} / \mathrm{hr}$ ) was administered intravenously while discontinuing isoflurane. Adequate anaesthesia was ensured by maintaining a stable arterial blood pressure and the absence of a withdrawal response to a paw pinch. The trachea was cannulated and the animal was mechanically ventilated during imaging sessions (1:2 oxygen/nitrogen ratio at 80 strokes $\mathrm{min}^{-1}$ and a tidal volume of $1 \mathrm{ml} / 100 \mathrm{~g}$ body weight). Body temperature was maintained at $37.0 \pm 0.5^{\circ} \mathrm{C}$. The $P \mathrm{O}_{2}, P \mathrm{PO}_{2}$, and $\mathrm{pH}$ of the arterial blood were periodically measured using a RAPIDLab 348EX blood gas analyzer (Siemens), and the ventilation parameters were adjusted to keep 
these variables within their physiological ranges $\left(\mathrm{PO}_{2}>80 \mathrm{~mm} \mathrm{Hg} ; \mathrm{PCO}_{2} 30-45 \mathrm{~mm} \mathrm{Hg}\right.$; and $\mathrm{pH}$ 7.35-7.45). Mean arterial blood pressure was stable at $90-110 \mathrm{~mm} \mathrm{Hg}$ throughout the experiment. The animal was secured in a stereotaxic frame and a craniotomy of approximately $4 \mathrm{~mm}$ diameter was carried out over the right primary somatosensory cortex, immediately caudal to the coronal suture and approximately $2-6 \mathrm{~mm}$ laterally from the midline. A durectomy was subsequently performed. One microliter of the $\mathrm{P} 2 \mathrm{X}_{1}$ antagonist NF449 $(5 \mu \mathrm{M})$ in artificial cerebrospinal fluid (aCSF; $124 \mathrm{mM} \mathrm{NaCl}, 3 \mathrm{mM} \mathrm{KCl}, 2 \mathrm{mM}$ $\mathrm{CaCl}_{2}, 26 \mathrm{mM} \mathrm{NaHCO}_{3}, 1.25 \mathrm{mM} \mathrm{NaH}_{2} \mathrm{PO}_{4}, 1 \mathrm{mM} \mathrm{MgSO}_{4}, 10 \mathrm{mM}$ D-glucose saturated with $95 \% \mathrm{O} 2 / 5 \% \mathrm{CO} 2$ [pH 7.4]), or one microliter of aCSF as a vehicle control, was pressure injected at 3-4 sites throughout the exposed cortical area, at a depth of $500 \mu \mathrm{m}$, using a glass micropipette. In order to distinguish cortical arterioles from venules and capillaries, Alexa 633 hydrazide $53(35 \mu \mathrm{M}, 1 \mu \mathrm{l})$ was included in the injection bolus. The cortical surface was covered with $0.8 \%$ agarose and a glass coverslip was placed on top. A custom built headplate was then attached to the skull and the entire assembly secured using dental cement. During imaging, the headplate was secured under the objective on a custom built stage.

\section{In vivo experiments: imaging}

Cortical vessel diameter was recorded using $2 \mathrm{P}$ microscopy of the intraluminal dye fluorescein isothiocyanate-dextran (FITC-dextran, MW $2000 \mathrm{kDa}, 50 \mathrm{mg} / \mathrm{kg}, 1 \mathrm{ml}$ i.v.). Two-photon excitation was carried out using a Newport-Spectraphysics Ti:Sapphire MaiTai laser pulsing at $80 \mathrm{MHz}$, and an Olympus FV1000 with XLPlan N 25x water immersion objective (NA 1.05). Acquisitions were carried out using a wavelength of $800 \mathrm{~nm}$ and the mean laser power under the objective was kept at $20-30 \mathrm{~mW}$. Penetrating arterioles were identified by chromatically separated Alexa 633 hydrazide fluorescent labelling of the smooth muscle elastin53. Recordings were made at a depth between 50 and $250 \mu \mathrm{m}$ from the cortical surface. XY-time series (at $1-4 \mathrm{~Hz}$ with a pixel dwell time of $2 \mu$ s and pixel size of $0.248-0.496 \mu \mathrm{m}$ ) were taken of regions of interest to record vessel dilations in response to somatosensory stimulation. Unilateral forepaw stimulation $(0.3 \mathrm{~ms}$ pulse width, $3 \mathrm{~Hz}, 0.2-2$ $\mathrm{mA}, 20 \mathrm{~s}$ ) was applied using an electrical stimulator triggered by a 1401 interface (Cambridge Electronic Design).

\section{In vivo experiments: analysis}

The presence of red blood cells (RBCs) leads to apparent holes in the images of the capillary and (to a lesser extent) the arteriole. This image noise was reduced by smoothing images in the time series with a rolling window (in time) maximum intensity projection not exceeding $2 \mathrm{~s}$ duration, as previously described6. The resulting time series was then median filtered (radius 1 pixel) using ImageJ. A 3-pixel wide line-segment was drawn perpendicular to the vessel in ImageJ and the fluorescence profile across the vessel was extracted. Relative diameter was determined by fitting a function to the fluorescence profile in Matlab (using the sum of 2 Gaussian functions), and calculating the full width at quarter-maximum of the peak fluorescence intensity. The peak dilation and the time to $10 \%$ of the peak dilation were calculated by fitting the data with a function of the form: (max dilation). $\left(\right.$ time $\left.^{n}\right) /\left(\right.$ time $\left.^{n}+K^{n}\right)$, with max dilation, $n$ and $K$ arbitrary constants 


\section{Statistics}

Data are shown as box and whisker plots in which the central line shows the median, the central dot shows the mean, the edges of the box define the upper and lower quartile values, and the outer whiskers show the minimum-maximum range of the data, or are shown as mean \pm s.e.m. $\mathrm{N}$ numbers on bars are of capillary regions or arterioles. The variability of responses observed at different regions (presumed regions of active pericyte control) along the same capillary was higher than that between different capillaries, slices or animals. Therefore, capillary regions that constricted to $200 \mathrm{nM}$ U46619 were used as the observational units. Normality of data was verified using the Kolmogorov-Smirnoff test and the equality of variance confirmed using the F-statistic. All data were compared to interleaved controls using a homoscedastic, two-sided Student's t-test (equal variance), except in Figs. 3c, 4j, 7f and Supp. Fig. 4d, where the variances of the data were unequal, and therefore a heteroscedastic, two-sided Student's t-test was used. Data in Supp. Fig. 2 were compared using a one-way ANOVA and corrected for multiple comparisons using a procedure equivalent to the Holm-Bonferroni method (for $\mathrm{N}$ comparisons, the most significant $\mathrm{p}$ value is multiplied by $\mathrm{N}$, the $2 \mathrm{nd}$ most significant by $\mathrm{N}-1$, the $3 \mathrm{rd}$ most significant by $\mathrm{N}-2$, etc.; corrected $\mathrm{p}$ values are significant if they are less than 0.05 ). An estimate of the sample size needed for a typical experiment is as follows: For a control response of $100 \%$, a typical response standard deviation of $40 \%$, a response in a drug of $30 \%$ (70\% inhibition), a power of $80 \%$ and $\mathrm{p}<0.05,7$ vessels are needed (http:// www.biomath.info/power/ttest.htm) in each of the control and drug groups. The exact numbers depend on the drug effect size and standard error of the data.

\section{Materials}

TTX, NBQX, D-AP5, S-MCPG, MRS2179 and A967079 were obtained from Tocris Biosciences; U46619, NF449, L-161982, U73122, CAY10441, PPOH, MAFP and FIPI from Cayman Chemicals; NS-398 and SC-560 from Calbiochem-Merck Millipore; RHC-80267 from Enzo Life Science; VU0155069 and CAY10594 from Santa Cruz; L-NNA, a, $\beta$ methylene ATP, NF023 and PGE 2 from Sigma; Alexa Fluor 488, Alexa Fluor 594, Fluo-4 pentapotassium salt, BAPTA tetrapotassium salt and Alexa Fluor 488 or FITC conjugated $\mathrm{IB}_{4}$ from Life Technologies; and PBS and Alexa Fluor 633 hydrazide from Thermo Scientific. All other salts and reagents were purchased from Sigma.

\section{Data Availability}

The data that support the findings of this study are available from the corresponding author upon request.

\section{Supplementary Material}

Refer to Web version on PubMed Central for supplementary material.

\section{Acknowledgements}

Supported by the European Research Council (BRAINPOWER to D.A. and NETSIGNAL to D.A.R.), a Fondation Leducq Transatlantic Network grant (to D.A.), a Wellcome Trust Programme Grant and Senior Investigator Award (075232 and 099222 to D.A.), a Wellcome Trust Senior Research Fellowship (095064 and 200893 to A.V.G.), a 
Wellcome Trust Principal Research Fellowship (101896 to D.A.R.), an EU FP7 grant (ITN EXTRABRAIN 606950 to D.A.R.) and an RSF grant (15-14-30000 to D.A.R.). We thank K. Zheng for help with 2-photon microscopy, and M. Carandini, I. Christie, S. Cockcroft, M. Ford, R. Jolivet, S. Mastitskaya and S. Sullivan for comments on the manuscript.

\section{References}

1. Zonta M, et al. Neuron-to-astrocyte signaling is central to the dynamic control of brain microcirculation. Nat Neurosci. 2003; 6:43-50. [PubMed: 12469126]

2. Mulligan SJ, Macvicar BA. Calcium transients in astrocyte endfeet cause cerebrovascular constrictions. Nature. 2004; 431:195-199. [PubMed: 15356633]

3. Takano T, et al. Astrocyte-mediated control of cerebral blood flow. Nat Neurosci. 2006; 9:260-267. [PubMed: 16388306]

4. Zimmermann KW. Der Feinere Bau der Blutcapillaren. Zeitschrift fur Anatomie und Entwicklungsgeschichte. 1923; 68:29-109.

5. Peppiatt CM, Howarth C, Mobbs P, Attwell D. Bidirectional control of CNS capillary diameter by pericytes. Nature. 2006; 443:700-704. [PubMed: 17036005]

6. Hall CN, et al. Capillary pericytes regulate cerebral blood flow in health and disease. Nature. 2014; 508:55-60. [PubMed: 24670647]

7. Hamel E. Perivascular nerves and the regulation of cerebrovascular tone. J Appl Physiol. 2006; 100:1059-1064. [PubMed: 16467392]

8. Attwell D, et al. Glial and neuronal control of brain blood flow. Nature. 2010; 468:232-243. [PubMed: 21068832]

9. Mishra A, Hamid A, Newman EA. Oxygen modulation of neurovascular coupling in the retina. Proc Natl Acad Sci USA. 2011; 108:17827-17831. [PubMed: 22006332]

10. Nizar K, et al. In vivo stimulus-induced vasodilation occurs without $\mathrm{IP}_{3}$ receptor activation and may precede astrocytic calcium increase. J Neurosci. 2013; 33:8411-8422. [PubMed: 23658179]

11. Winship IR, Plaa N, Murphy TH. Rapid astrocyte calcium signals correlate with neuronal activity and onset of the hemodynamic response in vivo. J Neurosci. 2007; 27:6268-6272. [PubMed: 17554000]

12. Reeves AM, Shigetomi E, Khakh BS. Bulk loading of calcium indicator dyes to study astrocyte physiology: key limitations and improvements using morphological maps. J Neurosci. 2011; 31:9353-9358. [PubMed: 21697385]

13. Lind BL, Brazhe AR, Jessen SB, Tan FC, Lauritzen MJ. Rapid stimulus-evoked astrocyte $\mathrm{Ca}^{2+}$ elevations and hemodynamic responses in mouse somatosensory cortex in vivo. Proc Natl Acad Sci USA. 2013; 110:E4678-E4687. [PubMed: 24218625]

14. Otsu Y, et al. Calcium dynamics in astrocyte processes during neurovascular coupling. Nat Neurosci. 2015; 18:210-218. [PubMed: 25531572]

15. Sun W, et al. Glutamate-dependent neuroglial calcium signaling differs between young and adult brain. Science. 2013; 339:197-200. [PubMed: 23307741]

16. Bonder DE, McCarthy KD. Astrocytic Gq-GPCR-linked $\mathrm{IP}_{3} \mathrm{R}$-dependent $\mathrm{Ca}^{2+}$ signaling does not mediate neurovascular coupling in mouse visual cortex in vivo. J Neurosci. 2014; 34:13139_ 13150. [PubMed: 25253859]

17. Seifert G, Steinhauser C. Glial cells in the mouse hippocampus express AMPA receptors with an intermediate Ca2+ permeability. Eur J Neurosci. 1995; 7:1872-1881. [PubMed: 8528461]

18. Lalo U, Pankratov Y, Kirchhoff F, North RA, Verkhratsky A. NMDA receptors mediate neuron-toglia signaling in mouse cortical astrocytes. J Neurosci. 2006; 26:2673-2683. [PubMed: 16525046]

19. Lalo $\mathrm{U}$, et al. $\mathrm{P} 2 \mathrm{X}_{1}$ and $\mathrm{P} 2 \mathrm{X}_{5}$ subunits form the functional $\mathrm{P} 2 \mathrm{X}$ receptor in mouse cortical astrocytes. J Neurosci. 2008; 28:5473-5480. [PubMed: 18495881]

20. Shigetomi E, Jackson-Weaver O, Huckstepp RT, O'Dell TJ, Khakh BS. TRPA1 channels are regulators of astrocyte basal calcium levels and long-term potentiation via constitutive D-serine release. J Neurosci. 2013; 33:10143-10153. [PubMed: 23761909]

21. Gordon GR, Choi HB, Rungta RL, Ellis-Davies GC, Macvicar BA. Brain metabolism dictates the polarity of astrocyte control over arterioles. Nature. 2008; 456:745-749. [PubMed: 18971930] 
22. Mishra A, et al. Imaging pericytes and capillary diameter in brain slices and isolated retinae. Nat Protoc. 2014; 9:323-336. [PubMed: 24434801]

23. Panatier A, Robitaille R. Astrocytic mGluR5 and the tripartite synapse. Neuroscience. 2015

24. Butt AM. ATP: a ubiquitous gliotransmitter integrating neuron-glial networks. Semin Cell Dev Biol. 2011; 22:205-213. [PubMed: 21376829]

25. Haustein MD, et al. Conditions and constraints for astrocyte calcium signaling in the hippocampal mossy fiber pathway. Neuron. 2014; 82:413-429. [PubMed: 24742463]

26. North RA. Molecular physiology of P2X receptors. Physiol Rev. 2002; 82:1013-1067. [PubMed: 12270951]

27. Shigetomi E, et al. Imaging calcium microdomains within entire astrocyte territories and endfeet with GCaMPs expressed using adeno-associated viruses. J Gen Physiol. 2013; 141:633-647.

[PubMed: 23589582]

28. Panatier A, et al. Astrocytes are endogenous regulators of basal transmission at central synapses. Cell. 2011; 146:785-798. [PubMed: 21855979]

29. Di Castro MA, et al. Local $\mathrm{Ca}^{2+}$ detection and modulation of synaptic release by astrocytes. Nat Neurosci. 2011; 14:1276-1284. [PubMed: 21909085]

30. Meng W, Tobin JR, Busija DW. Glutamate-induced cerebral vasodilation is mediated by nitric oxide through N-methyl-D-aspartate receptors. Stroke. 1995; 26:857-862. [PubMed: 7740580]

31. Stobart JL, Lu L, Anderson HD, Mori H, Andersona CM. Astrocyte-induced cortical vasodilation is mediated by D-serine and endothelial nitric oxide synthase. Proc Natl Acad Sci USA. 2013; 110:3149-3154. [PubMed: 23386721]

32. Alkayed NJ, et al. Molecular characterization of an arachidonic acid epoxygenase in rat brain astrocytes. Stroke. 1996; 27:971-979. [PubMed: 8623121]

33. Stephenson DT, et al. Calcium-sensitive cytosolic phospholipase $\mathrm{A}_{2}\left(\mathrm{cPLA}_{2}\right)$ is expressed in human brain astrocytes. Brain Res. 1994; 637:97-105. [PubMed: 8180824]

34. Cockcroft S. Signalling roles of mammalian phospholipase D1 and D2. Cell Mol Life Sci. 2001; 58:1674-1687. [PubMed: 11706993]

35. Sarri E, Pardo R, Fensome-Green A, Cockcroft S. Endogenous phospholipase D2 localizes to the plasma membrane of RBL-2H3 mast cells and can be distinguished from ADP ribosylation factorstimulated phospholipase D1 activity by its specific sensitivity to oleic acid. Biochem J. 2003; 369:319-329. [PubMed: 12374567]

36. Yemisci M, et al. Pericyte contraction induced by oxidative-nitrative stress impairs capillary reflow despite successful opening of an occluded cerebral artery. Nat Med. 2009; 15:1031-1037. [PubMed: 19718040]

37. Duffy S, Macvicar BA. Adrenergic calcium signaling in astrocyte networks within the hippocampal slice. J Neurosci. 1995; 15:5535-5550. [PubMed: 7643199]

38. Calcinaghi N, et al. Metabotropic glutamate receptor mGluR5 is not involved in the early hemodynamic response. J Cereb Blood Flow Metab. 2011; 31:e1-10.

39. Srinivasan $\mathrm{R}$, et al. $\mathrm{Ca}^{2+}$ signaling in astrocytes from $\mathrm{Ip} 3 \mathrm{r} 2^{-/-}$mice in brain slices and during startle responses in vivo. Nat Neurosci. 2015; 18:708-717. [PubMed: 25894291]

40. Wells JA, et al. A critical role for purinergic signalling in the mechanisms underlying generation of BOLD fMRI responses. J Neurosci. 2015; 35:5284-5292. [PubMed: 25834053]

41. Wieraszko A, Goldsmith G, Seyfried TN. Stimulation-dependent release of adenosine triphosphate from hippocampal slices. Brain Res. 1989; 485:244-250. [PubMed: 2566360]

42. Zhang Y, et al. An RNA-Seq transcriptome and splicing database of glia, neurons, and vascular cells of the cerebral cortex. J Neurosci. 2014; 34:11929-11947. [PubMed: 25186741]

43. Tricoire L, Vitalis T. Neuronal nitric oxide synthase expressing neurons: a journey from birth to neuronal circuits. Front Neural Circuits. 2012; 6:82. [PubMed: 23227003]

44. Schmidt HH, Pollock JS, Nakane M, Förstermann U, Murad F. $\mathrm{Ca}^{2+} /$ calmodulin-regulated nitric oxide synthase. Cell Calcium. 1992; 13:427-434. [PubMed: 1380405]

45. Lindauer U, Megow D, Matsuda H, Dirnagl U. Nitric oxide: a modulator, but not a mediator, of neurovascular coupling in rat somatosensory cortex. Am J Physiol Heart Circ Physiol. 1999; 277:H799-H811. 
46. Metea MR, Newman EA. Glial cells dilate and constrict blood vessels: a mechanism of neurovascular coupling. J Neurosci. 2006; 26:2862-2870. [PubMed: 16540563]

47. Lecrux C, Kocharyan A, Sandoe CH, Tong XK, Hamel E. Pyramidal cells and cytochrome P450 epoxygenase products in the neurovascular coupling response to basal forebrain cholinergic input. J Cereb Blood Flow Metab. 2012; 32:896-906. [PubMed: 22293985]

48. Farooqui AA, Yang HC, Rosenberger TA, Horrocks LA. Phospholipase A2 and its role in brain tissue. J Neurochem. 1997; 69:889-901. [PubMed: 9282910]

49. Zhang Y, et al. Increased expression of two phospholipase D isoforms during experimentally induced hippocampal mossy fiber outgrowth. Glia. 2004; 46:74-83. [PubMed: 14999815]

50. Blinder P, et al. The cortical angiome: an interconnected vascular network with noncolumnar patterns of blood flow. Nature Neurosci. 2013; 16:889-897. [PubMed: 23749145]

51. Kur J, Newman EA. Purinergic control of vascular tone in the retina. J Physiol. 2014; 592:491504. [PubMed: 24277867]

52. Peters BP, Goldstein IJ. The use of fluorescein-conjugated Bandeiraea simplicifolia B4-isolectin as a histochemical reagent for the detection of alpha-D-galactopyranosyl groups. Their occurrence in basement membranes. Exp Cell Res. 1979; 120:321-334. [PubMed: 436961]

53. Shen Z, Lu Z, Chhatbar PY, O'Herron P, Kara P. An artery-specific fluorescent dye for studying neurovascular coupling. Nature Meth. 2012; 9:273-276.

54. Nakatsuka A, Mizuno R, Ono N, Nakayama J, Ohhashi T. Arachidonic acid-induced COX-1 and COX-2-mediated vasodilation in rat gingival arterioles in vivo. Jpn J Physiol. 2005; 55:293-302. [PubMed: 16281994]

55. Ito $\mathrm{S}$, et al. Roles of stretch-activated cation channel and Rho-kinase in the spontaneous contraction of airway smooth muscle. Eur J Pharmacol. 2006; 552:135-142. [PubMed: 17026989]

56. Wang MH, et al. Cytochrome P450-derived arachidonic acid metabolism in the rat kidney: characterization of selective inhibitors. J Pharmacol Exp Ther. 1998; 284:966-973. [PubMed: 9495856]

57. Bley KR, et al. RO1138452 and RO3244794: characterization of structurally distinct, potent and selective IP (prostacyclin) receptor antagonists. Br J Pharmacol. 2006; 147:335-345. [PubMed: 16331286]

58. Myren M, Olesen J, Gupta S. Pharmacological and expression profile of the prostaglandin I(2) receptor in the rat craniovascular system. Vascul Pharmacol. 2011; 55:50-58. [PubMed: 21749934]

59. Shin KJ, et al. Phospholipase $\mathrm{A}_{2}$-mediated $\mathrm{Ca}^{2+}$ influx by 2,2',4,6-tetrachlorobiphenyl in PC12 cells. Toxicol Appl Pharmacol. 2002; 178:37-43. [PubMed: 11781078]

60. Smith RJ, et al. Receptor-coupled signal transduction in human polymorphonuclear neutrophils: effects of a novel inhibitor of phospholipase C-dependent processes on cell responsiveness. $\mathrm{J}$ Pharmacol Exp Ther. 1990; 253:688-697. [PubMed: 2338654]

61. Su W, et al. 5-Fluoro-2-indolyl des-chlorohalopemide (FIPI), a phospholipase D pharmacological inhibitor that alters cell spreading and inhibits chemotaxis. Mol Pharmacol. 2009; 75:437-446. [PubMed: 19064628]

62. Scott SA, et al. Design of isoform-selective phospholipase D inhibitors that modulate cancer cell invasiveness. Nat Chem Biol. 2009; 5:108-117. [PubMed: 19136975]

63. Weigl L, Zidar A, Gscheidlinger R, Karel A, Hohenegger M. Store operated $\mathrm{Ca}^{2+}$ influx by selective depletion of ryanodine sensitive $\mathrm{Ca}^{2+}$ pools in primary human skeletal muscle cells. Naunyn Schmiedebergs Arch Pharmacol. 2003; 367:353-363. [PubMed: 12690427]

64. Rettinger J, et al. Profiling at recombinant homomeric and heteromeric rat P2X receptors identifies the suramin analogue NF449 as a highly potent $\mathrm{P}_{2} \mathrm{X}_{1}$ receptor antagonist. Neuropharmacol. 2005; 48:461-468.

65. Soto F, Lambrecht G, Nickel P, Stuhmer W, Busch AE. Antagonistic properties of the suramin analogue NF023 at heterologously expressed P2X receptors. Neuropharmacol. 1999; 38:141-149. 
a $\quad 446619$

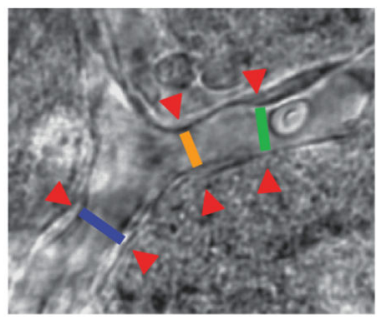

C

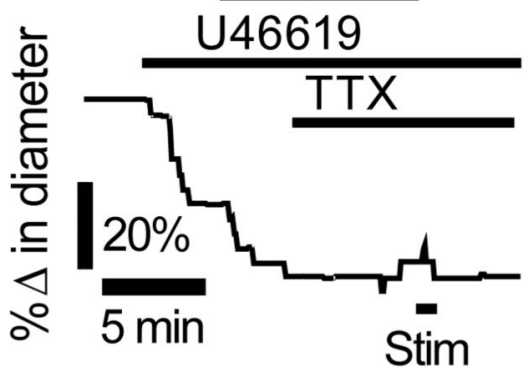

5

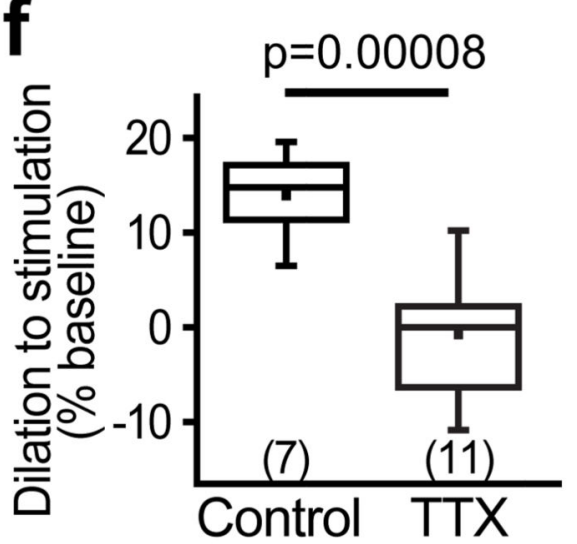

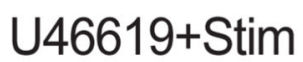

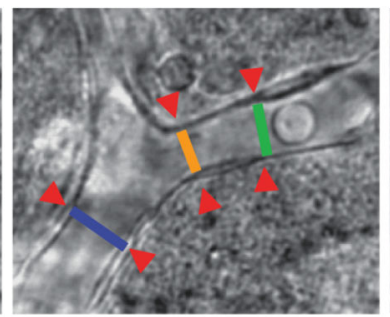

d AMPA

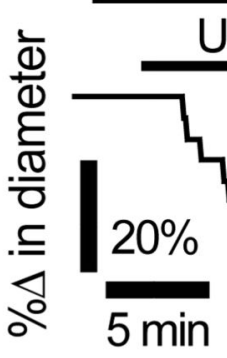

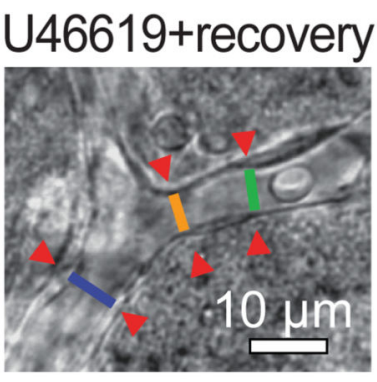

AMPA receptor

U46619

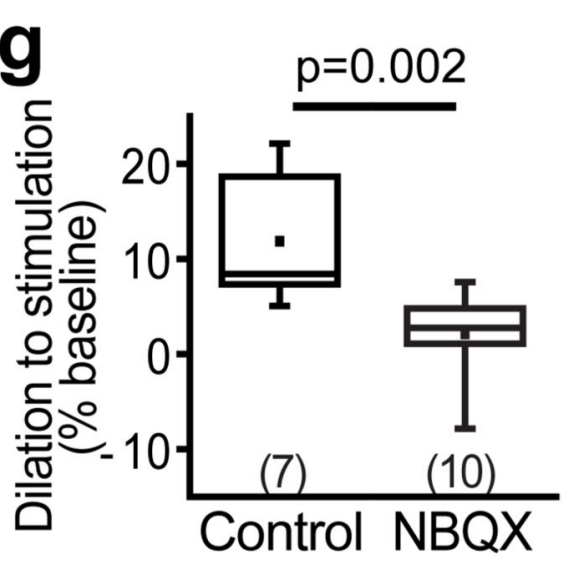

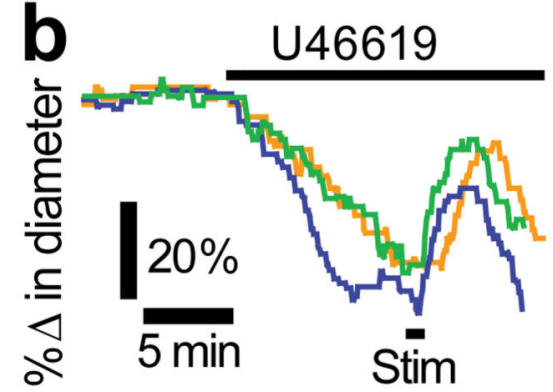

e NMDA receptor
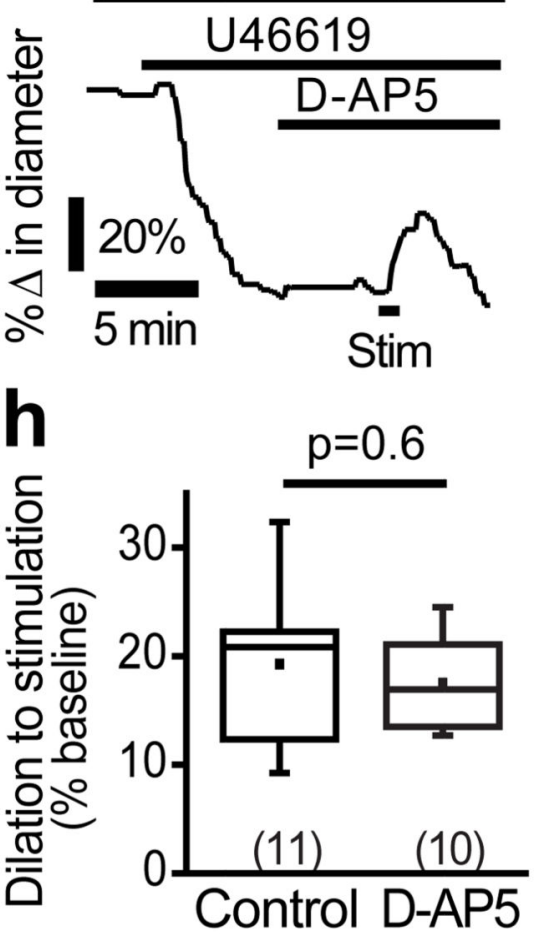

Figure 1. Neuronal activity evokes capillary dilation.

(a) A cortical capillary response to $200 \mathrm{nM}$ U46619 and superimposed neuronal stimulation (stim). Lines show lumen diameters plotted in b. (b) U46619 evoked constriction and stimulation-evoked dilation at regions indicated in a (in this and subsequent example traces, a large response is shown for illustrative purposes). (c) $500 \mathrm{nM}$ TTX blocks stimulationevoked capillary dilation. (d) $10 \mu \mathrm{M}$ NBQX blocks stimulation-evoked dilation. (e) $25 \mu \mathrm{M}$ D-AP5 did not reduce stimulation-evoked dilation. (f-h) Mean data showing the block of capillary dilation by TTX (f) and NBQX (g) but not by D-AP5 (h). Numbers on bars are capillary regions (putative pericytes) studied. Data are shown as box and whisker plots as defined in the Statistics part of the Methods. 

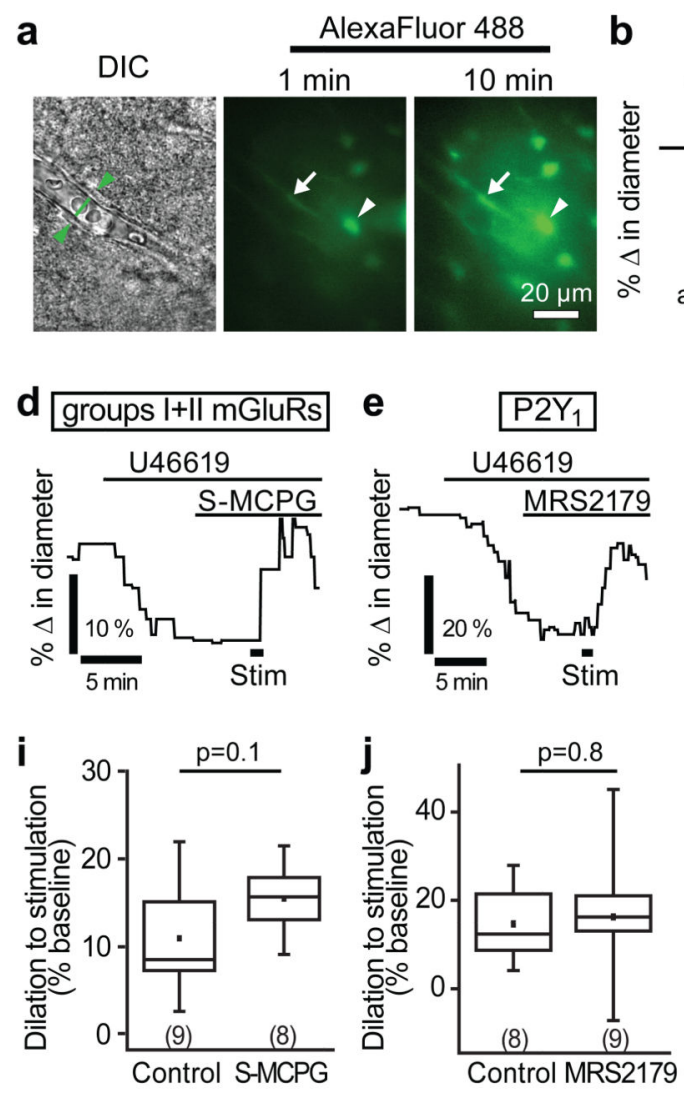

Control MRS2179
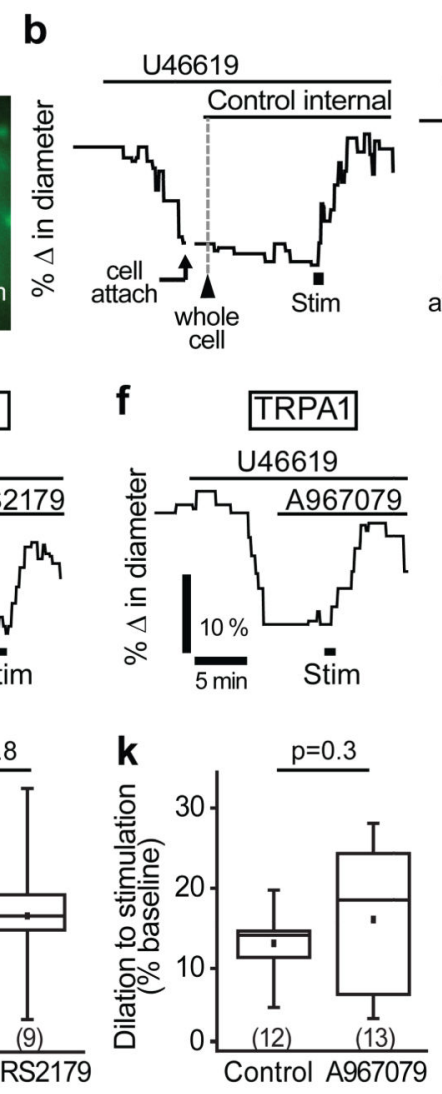
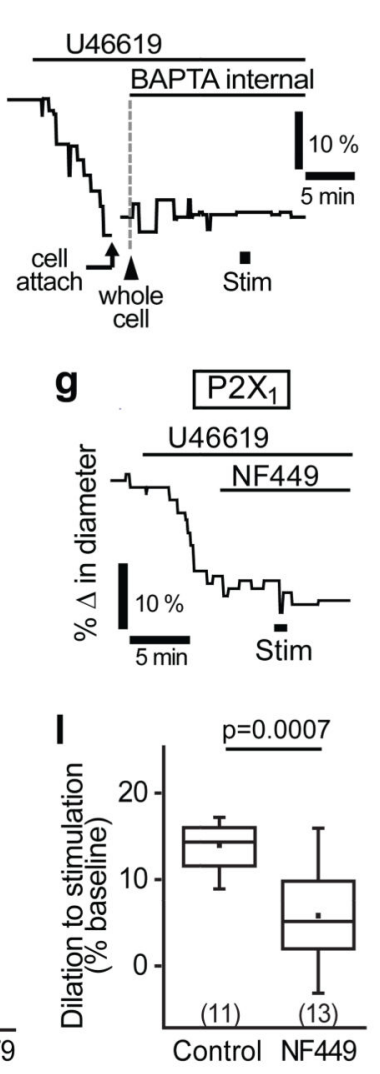
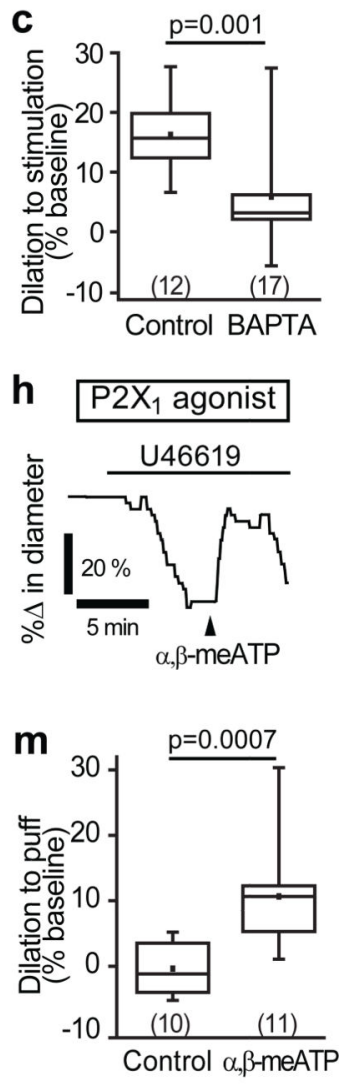

Figure 2. $\mathrm{P}_{2} \mathrm{X}_{1}$-evoked astrocyte $\mathrm{Ca}^{2+}$ signalling mediates capillary-level neurovascular coupling. (a) A DIC image of a cortical capillary (left panel) and the AlexaFluor 488 fill of the astrocyte network after whole-cell patch-clamp dialysis for $1 \mathrm{~min}$ (middle) and $10 \mathrm{mins}$ (right) after breaking into the cell. Whole-cell patch-clamped cell is indicated by arrowhead and endfoot indicated by arrow. (b) Example traces and (c) mean data demonstrating that stimulation-evoked capillary dilation is intact when the astrocyte network is dialyzed with a control internal solution containing $1 \mathrm{mM}$ EGTA but significantly reduced when filled with $30 \mathrm{mM}$ BAPTA, a fast $\mathrm{Ca}^{2+}$-chelator. (d-f) An inhibitor of group I and II mGluRs, S-MCPG ( $1 \mathrm{mM}$; d), the P2Y 1 blocker MRS2179 (25 $\mu \mathrm{M}$; e) and the TRPA1 blocker A967079 (10 $\mu \mathrm{M}$; f) do not block stimulation-evoked capillary dilation. (g) The P2X 1 blocker NF449 (100 $\mathrm{nM}$ ) significantly reduced stimulation-evoked capillary dilation. (h) Puff-application of the P2X 1 agonist $a, \beta$-methylene ATP $(a, \beta$-meATP, $100 \mu \mathrm{M})$ to the neuropil downstream of the vessel induces capillary dilation. (i-l) Quantification of the effect of S-MCPG (i), MRS2179 (j), A967079 (k) and NF449 (l) on capillary dilation. (m) Mean response of capillaries in experiments like those in $\mathrm{h}$, puffing external solution (control) or $a, \beta$-methylene ATP. Change in diameter in control experiments was measured as a $30 \mathrm{~s}$ average centred around the largest response seen between 30 and $120 \mathrm{~s}$ after puff of $a, \beta$-methylene ATP. Data are shown as box and whisker plots as defined in the Statistics part of the Methods. 

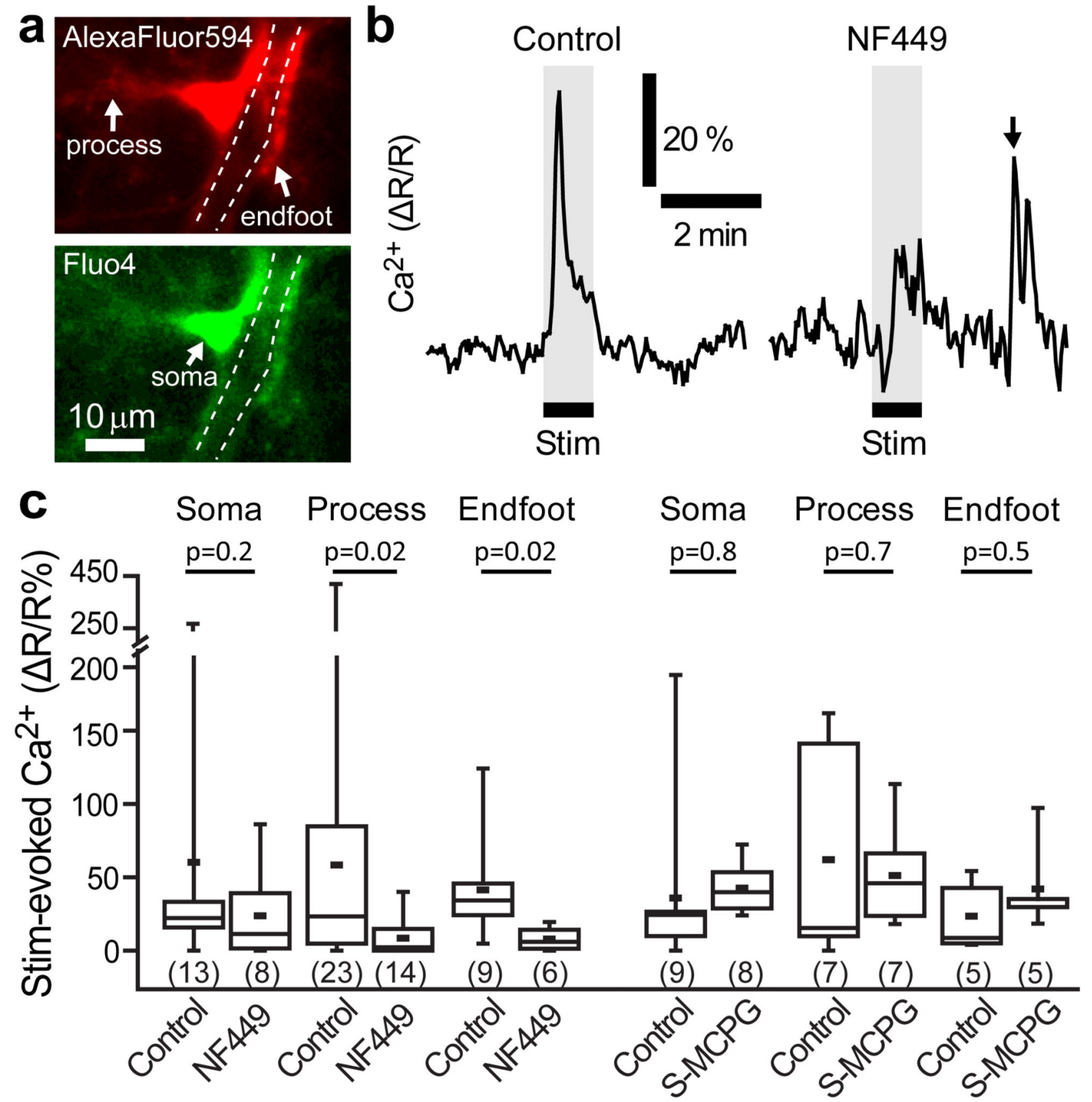

Figure 3. Neuronally-evoked astrocyte $\left[\mathrm{Ca}^{2+}\right]_{i}$ rise depends on $\mathrm{P}_{2} \mathrm{X}_{1}$ receptors.

(a) An astrocyte patch-loaded with AlexaFluor 594 (top) and Fluo4 (bottom) showing the processes, endfoot and soma. White dashed lines delineate the vessel lumen ensheathed by the endfoot process. (b) Neuronal stimulation evoked a $\left[\mathrm{Ca}^{2+}\right]_{\mathrm{i}}$ rise in astrocyte endfeet in control conditions (left); the rise was smaller in the presence of the $\mathrm{P} 2 \mathrm{X}_{1}$ blocker NF449 (100 nM, right). Arrow indicates a spontaneous $\mathrm{Ca}^{2+}$ transient, demonstrating that Fluo-4 could still detect $\left[\mathrm{Ca}^{2+}\right]_{\mathrm{i}}$ transients with NF449 present. (c) Mean change in neuronallyevoked astrocyte $\left[\mathrm{Ca}^{2+}\right]_{i}$ in somata, processes and endfeet in the absence and presence of 
different blockers. NF449 (black bars), a blocker of P2X1 channels, significantly reduced the $\left[\mathrm{Ca}^{2+}\right]$ rise in processes and endfeet, but S-MCPG, a blocker of groups I and II mGluRs had no effect on astrocyte $\left[\mathrm{Ca}^{2+}\right]$ in any compartment (grey bars). Time to $10 \%$ of the peak and to the peak $\left[\mathrm{Ca}^{2+}\right]$ change in endfeet were $5.27+1.15 \mathrm{~s}$ and $11.57+2.39 \mathrm{~s}$ respectively. Data are shown as box and whisker plots as defined in the Statistics part of the Methods. 


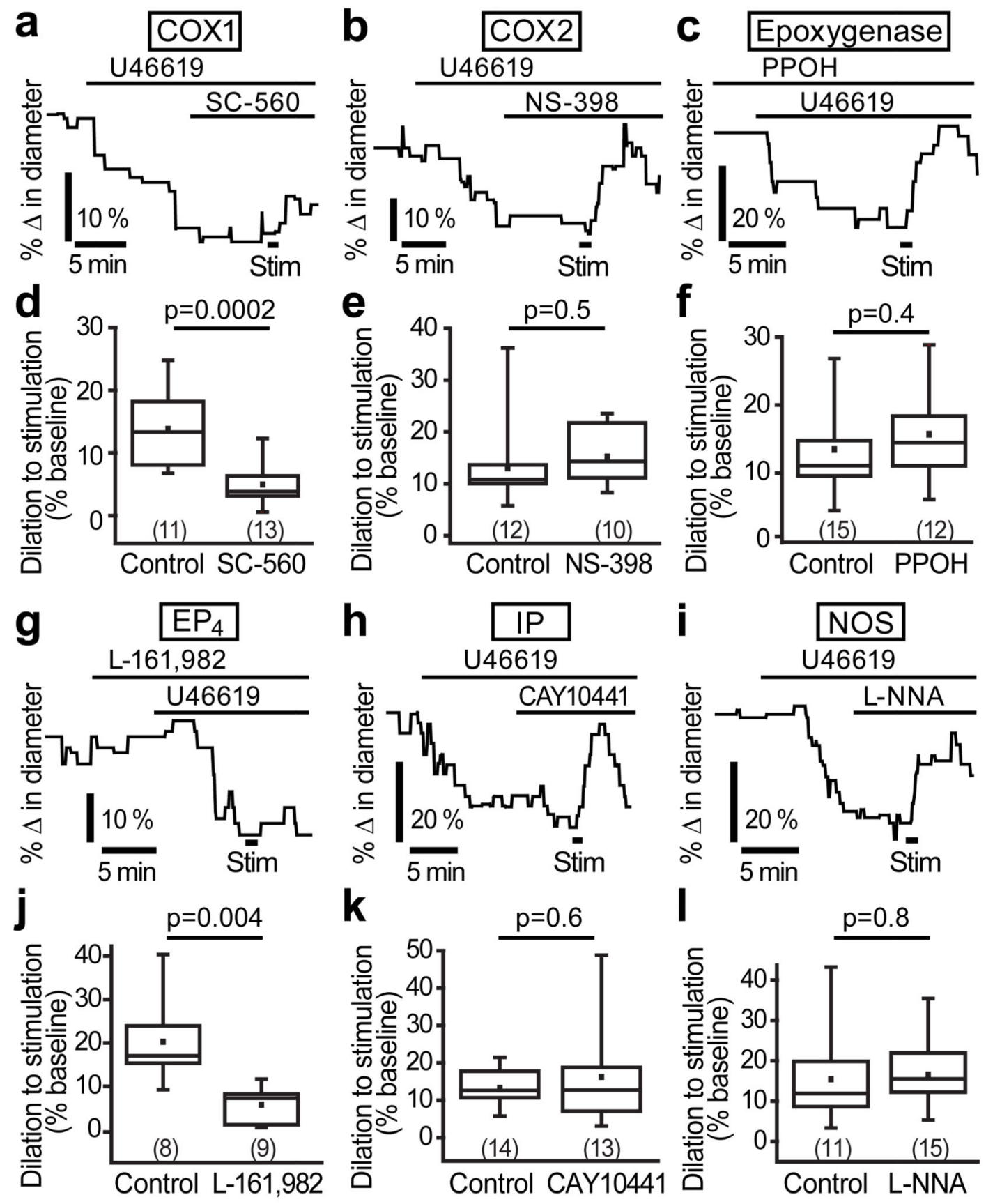

Figure 4. AA metabolites mediating stimulation-evoked capillary dilation.

(a) The COX1 blocker SC-560 (1 $\mu \mathrm{M})$ blocks the dilation. (b,c) The COX2 blocker NS-398 $(10 \mu \mathrm{M} ; \mathbf{b})$ and the epoxygenase inhibitor PPOH $(25 \mu \mathrm{M}$; c) had no effect on the dilation. (df) Mean data for the effect of SC-560 (d), NS-398 (e) and PPOH (f) on capillary dilation. (g) Blocking the $\mathrm{PGE}_{2}$ receptor $\mathrm{EP}_{4}$ with L-161,982 (1 $\left.\mu \mathrm{M}\right)$ inhibits dilation. (h,i) Blocking the $\mathrm{PGI}_{2}$ receptor IP with CAY10441 ( $1 \mu \mathrm{M}$; h) or NO synthase with L-NNA (100 $\mu \mathrm{M}$; i) has no effect on capillary dilation. (j-l) Mean data showing that capillary dilation is blocked by 
L-161,982 (j), but not by CAY10441 (k) or L-NNA (I). Data are shown as box and whisker plots as defined in the Statistics part of the Methods. 

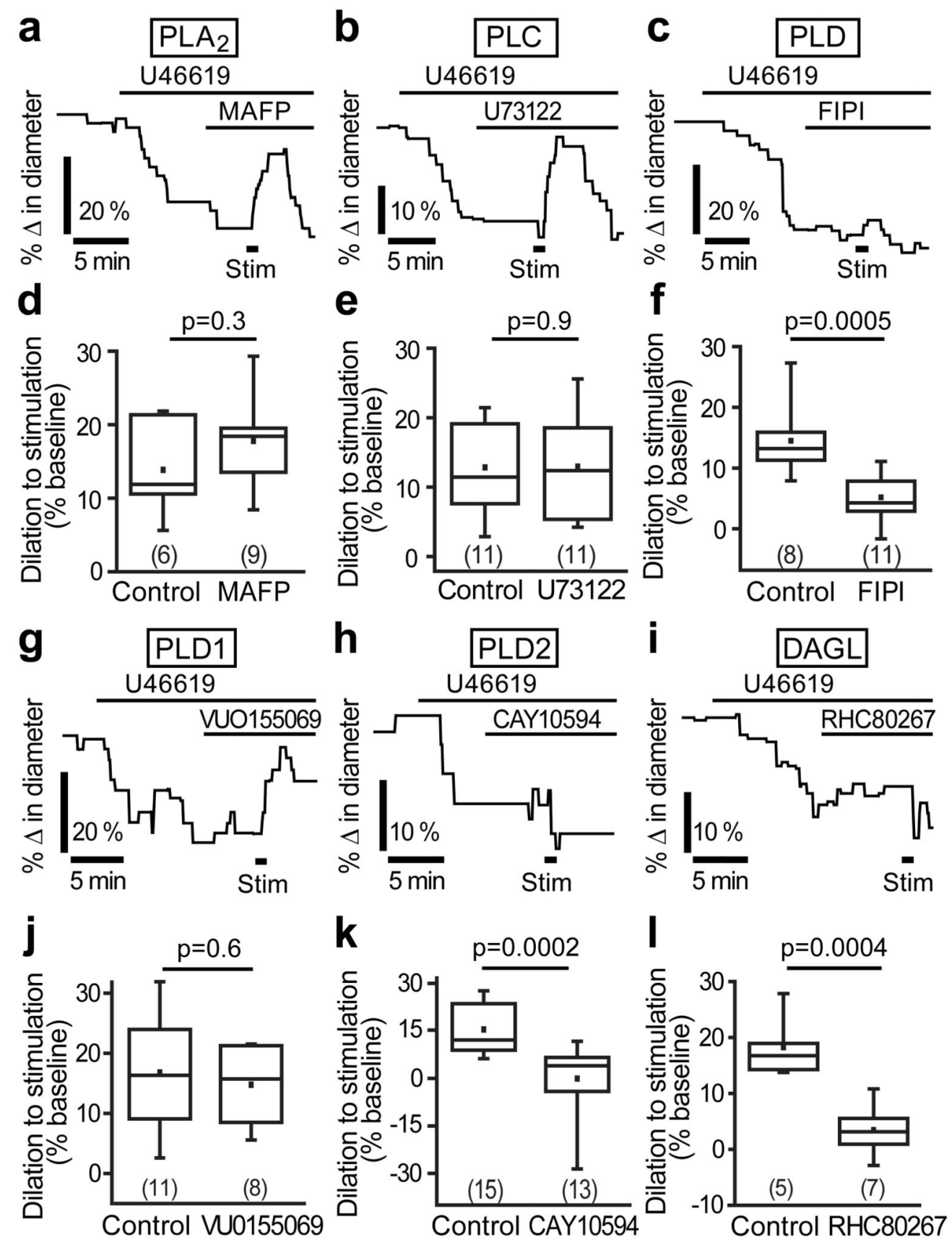

Figure 5. PLD2, not PLA2, initiates neurovascular coupling at the capillary level.

(a) The PLA 2 inhibitor MAFP $(10 \mu \mathrm{M})$ does not block stimulation-evoked capillary dilation.

(b) The PLC blocker, U73122 (10 $\mu \mathrm{M})$, does not reduce dilation. (c) The PLD blocker FIPI $(1 \mu \mathrm{M})$ inhibits dilation. (d-f) Mean data showing the effects of MAFP (d), U73122 (e) and FIPI (f) on capillary dilation. (g) Blocking PLD1 with VU0155069 (500 nM) had no effect on the dilation. (h-i) The PLD2 blocker CAY10594 $(1 \mu \mathrm{M} ; \mathbf{h})$ and the DAGL blocker RHC80267 (50 $\mu \mathrm{M}$; i) significantly reduce the capillary dilation. (j-l) Mean data showing 
the effect of VU0155069 (j), CAY10594 (k) and RHC80267 (l) on capillary dilation. Data are shown as box and whisker plots as defined in the Statistics part of the Methods. 
a

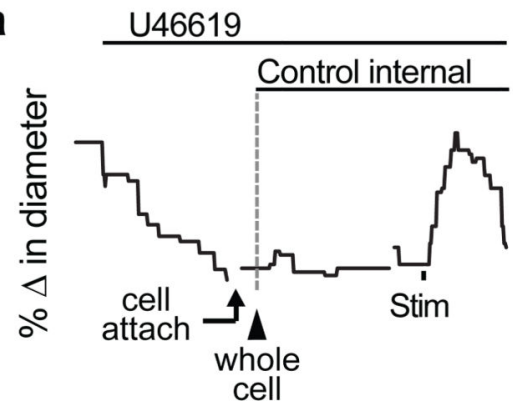

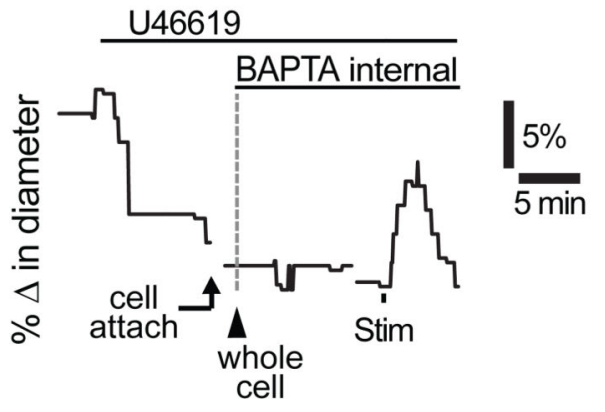

b
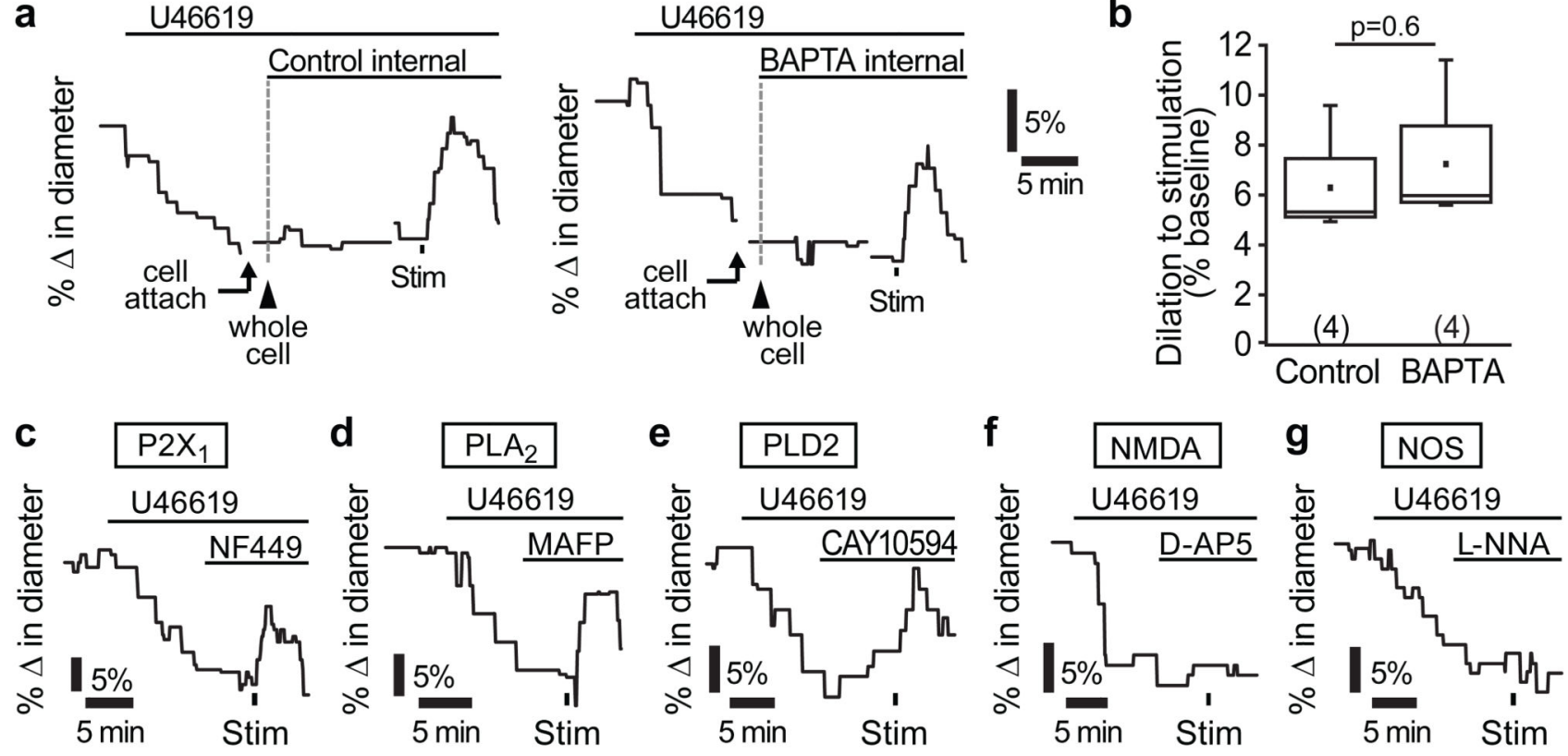

h

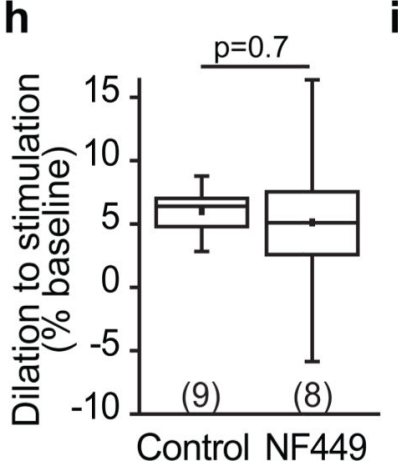

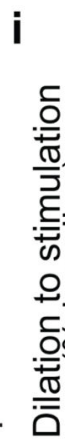

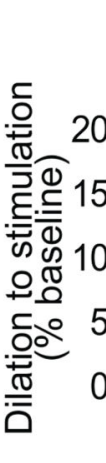

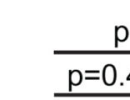

$=0.5$

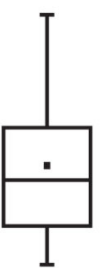

(6)
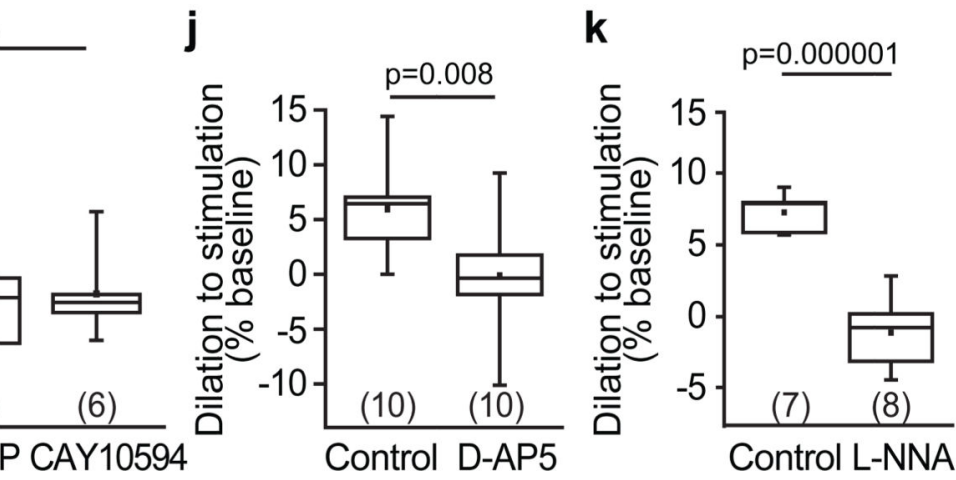

Figure 6. Neurovascular signalling to arterioles is mediated by NMDAR and NOS activity, and not by astrocyte $\mathrm{Ca}^{2+}$.

(a) Example traces and (b) mean data demonstrating that stimulation-evoked arteriole dilation is not altered when the astrocyte network is dialyzed with $30 \mathrm{mM}$ BAPTA, a fast $\mathrm{Ca}^{2+}$-chelator, compared to a control internal solution containing $1 \mathrm{mM}$ EGTA. (c-e) The P2X 1 blocker NF449 (100 nM; c), the PLA 2 inhibitor MAFP (10 $\mu \mathrm{M}$; d) and the PLD2 blocker CAY10594 (1 $\mu \mathrm{M}$; e) do not block stimulation-evoked arteriole dilation. (f-g) The NMDA receptor blocker D-AP5 $(25 \mu \mathrm{M}$; f) and the NO synthase blocker L-NNA (100 $\mu \mathrm{M}$; g) abolished the arteriole dilation. Mean data showing the effect of NF449 (h), MAFP (i), CAY10594 (i), D-AP5 (j) and L-NNA (k) on arteriole dilation. Data are shown as box and whisker plots as defined in the Statistics part of the Methods. 
a

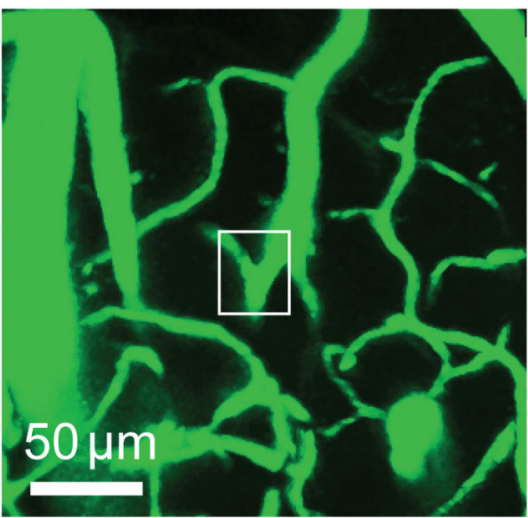

C

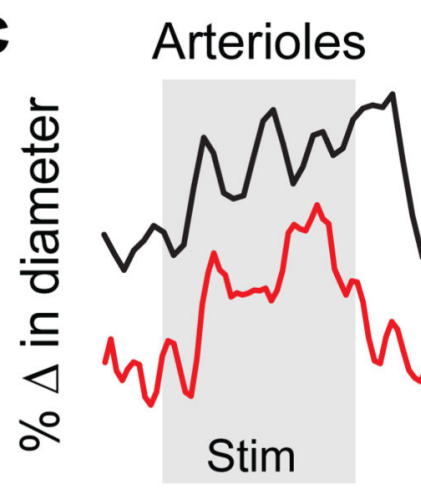

b

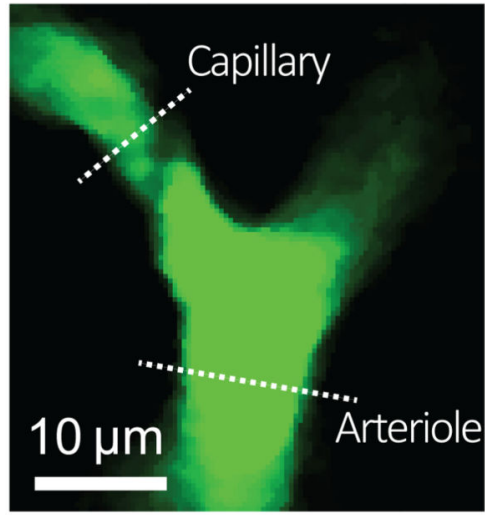

d Capillaries

$20 \%$

e
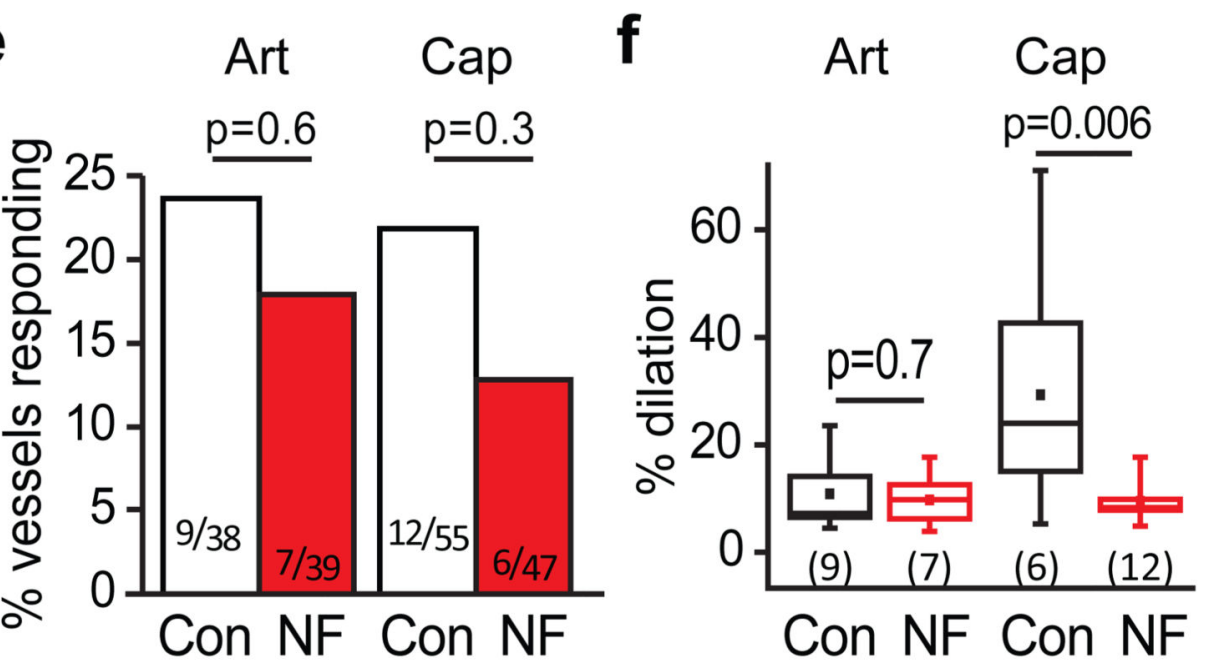

Figure 7. Neurovascular signalling to capillaries in vivo is mediated by $\mathrm{P}_{2} \mathrm{X}_{1}$ receptors.

(a) Two-photon stack ( $90 \mu \mathrm{m}$ thick, maximum intensity projection) of FITC-dextran-filled vessels (green) in the somatosensory cortex of an anaesthetised rat. (b) Enlarged image showing a penetrating arteriole with a capillary branching off it. (c-d) Example traces of forepaw stimulation-evoked dilation of arterioles (c) and capillaries (d) in the presence of vehicle (aCSF, black traces) or the $\mathrm{P}_{2} \mathrm{X}_{1}$ blocker NF449 (5 $\mu \mathrm{M}$; red traces). Capillary dilations occurred faster than arteriole dilations (time to $10 \%$ dilation was $3.0 \pm 0.8$ s for 12 capillaries and $5.1 \pm 1.7$ s for 9 arterioles), as previously reported ${ }^{6}$; however, reflecting the 
smaller number of vessels studied, this effect did not reach significance in this study ( $\mathrm{p}=0.3$ ). (e) The percentage of arterioles (Art) and capillaries (Cap) that dilated in response to stimulation was not significantly different in NF449 and vehicle-treated animals. (f) Forepaw stimulation-evoked mean arteriolar dilation was similar in vehicle and NF449 treated animals, but capillary dilation was significantly inhibited by NF449. Data are shown as box and whisker plots as defined in the Statistics part of the Methods. 